\title{
Análise computacional do genoma e transcritoma de Plasmodium vivax: contribuições da bioinformática para o estudo da malária
}

\author{
Bruna Renata Silva Corrêa \\ DISSERTAÇÃO APRESENTADA \\ $A O$ \\ PROGRAMA INTERUNIDADES EM BIOINFORMÁTICA \\ DA \\ UNIVERSIDADE DE SÃO PAULO \\ PARA \\ OBTENÇÃO DO GRAU DE MESTRE \\ EM \\ CIÊNCIAS \\ Área de Concentração: Bioinformática \\ Orientador: Prof. Dr. Ricardo Zorzetto Nicoliello Vêncio
}

Ribeirão Preto

2012 


\section{BRUNA RENATA SILVA CORRÊA}

Análise computacional do genoma e transcritoma de Plasmodium vivax: contribuições da bioinformática para o estudo da malária

Dissertação apresentada ao Programa de Pós-Graduação Interunidades em Bioinformática para a obtenção do título de Mestre em Ciências.

Área de concentração: Bioinformática

Orientador: Prof. Dr. Ricardo Zorzetto Nicoliello Vêncio

Ribeirão Preto

2012 
CORRÊA, B.R.S. Análise Computacional do Genoma e Transcritoma de Plasmodium vivax: Contribuições da Bioinformática para o Estudo da Malária. Dissertação apresentada ao Programa de Pós-Graduação Interunidades em Bioinformática para a obtenção do título de Mestre em Ciências.

Aprovada em:

Banca Examinadora

Prof. Dr. Instituição:

Julgamento: Assinatura:

Prof. Dr. Instituição:

Julgamento: Assinatura:

Prof. Dr. Instituição:

Julgamento: Assinatura: 


\section{Resumo}

CORRÊA, B.R.S. Análise Computacional do Genoma e Transcritoma de Plasmodium vivax: Contribuições da Bioinformática para o Estudo da Malária 2012 [Dissertação de mestrado]. Faculdade de Filosofia, Ciências e Letras de Ribeirão Preto, Departamento de Computação e Matemática, Universidade de São Paulo, Ribeirão Preto, 2012.

Plasmodium vivax é o parasita causador de malária humana com maior distribuição global, responsável pela redução da qualidade de vida de milhões de pessoas ao redor do mundo. O objetivo geral do trabalho foi contribuir, através de metodologias estatísticas e de bioinformática, para o entendimento do mecanismo de escape da eliminação pelo baço do hospedeiro utilizado por $P$. vivax. Para isso, primeiramente realizou-se a análise estatística de um experimento de transcritômica, através de microarrays. Esse experimento foi conduzido previamente pelo grupo de colaboradores do presente estudo, utilizando um modelo animal, Aotus lemurinus griseimembra, com o objetivo de identificar genes de $P$. vivax expressos somente em parasitas retirados de macacos que possuíam o baço intacto. Em uma segunda fase, foi projetado um tiling array contendo todos os éxons e as regiões 5'UTR e 3'UTR disponíveis do genoma de $P$. vivax, que será utilizado para a realização de mais investigações a respeito da influência da presença do baço na expressão gênica de $P$. vivax. Na última etapa, foi conduzida uma melhoria na anotação funcional do genoma de $P$. vivax, através de uma metodologia automática, com o objetivo de adicionar informações para auxiliar na interpretação biológica dos resultados obtidos anteriormente.

Palavras-chave: Bioinformática, Transcritoma, Plasmodium vivax, Malária, Anotação Funcional 


\section{Abstract}

CORREAA, B.R.S. Computational Analysis of the Plasmodium vivax Transcriptome and Genome: Bioinformatics Contributions for the Malaria Investigation 2012 [Master Thesis]. Faculdade de Filosofia, Ciências e Letras de Ribeirão Preto, Departamento de Computação e Matemática, Universidade de São Paulo, Ribeirão Preto, 2012.

Plasmodium vivax is the parasite that causes the human malaria type with the largest global distribution and it is responsible for quality of life impairment of millions of people around the world. The general purpose of this study was to contribute to understand the mechanism used by P. vivax to scape from the host spleen elimination, through statistical methodologies and bioinformatics. First of all, we carried out statistical analysis of a microarray experiment conducted earlier by the collaborators of this study, using Aotus lemurinus griseimembra as model organism, in order to identify genes of $P$. vivax expressed only in parasites extracted from monkeys with intact spleen. In the second step, we designed a tiling array containing 5'UTR, 3'UTR and all the exons of the P. vivax genome, which will be used to perform more experiments to investigate the role of the spleen on the parasite gene expression. In the last step, we add information to the functional annotation of $P$. vivax genome, through an automated methodology, to improve the biological interpretation of the results obtained previously.

Keywords: Bioinformatics, Transcriptome, Plasmodium vivax, Malaria, Functional Annotation 


\section{Lista de Figuras}

Figura 1 - Mapa do risco de malária por infecção de P. vivax.

pg. 11

Figura 2 - Ciclo de vida de P. vivax no hospedeiro humano e no mosquito vetor.

pg. 13

Figura 3 - Modelo de escape do parasita da eliminação pelo baço.

pg. 16

Figura 4 - Visão geral de um experimento de microarray.

pg. 18

Figura 5 - Tipos de design de sondas de tiling array.

pg. 19

Figura 6 - Redução dos custos de sequenciamento de genomas ao longo dos anos.

pg. 21

Figura 7 - Representação da estrutura e relações dos termos GO.

pg. 22

Figura 8 - Representação esquemática das regiões da lâmina de microarray.

pg. 26

Figura 9 - Representação da modelagem das regiões de foreground e background.

pg. 27

Figura 10 - Representação do segundo modelo de busca por genes expressos e não-expressos. pg. 28

Figura 11 - Representação do padrão de expressão de interesse no terceiro método proposto.

pg. 29

Figura 12 - Tipos de sequências disponíveis no banco de dados PlasmoDB.

pg. 30

Figura 13 - Etapas de criação de um array através da ferramenta eArray da empresa Agilent ${ }^{\mathrm{TM}}$.

pg. 34

Figura 14 - Método de anotação por classificação utilizando SVM.

pg. 35

Figura 15 - Padrão de expressão dos genes resultantes da primeira análise.

pg. 38

Figura 16 - Lâmina de microarray destacando as regiões comparadas no segundo modelo.

pg. 39

Figura 17 - Número de genes encontrados em cada uma das abordagens.

pg. 40

Figura 18 - Principais termos encontrados na descrição dos produtos gênicos de $P$. vivax.

pg. 41

Figura 19 - Resultados quantitativos da anotação obtida através do método GOPET.

pg. 42

Figura 20 - Principais termos GO associados às proteínas de $P$. Vivax.

pg. 43

Figura 21 - Número de anotações obtidas em cada nível da ontologia GO.

pg. 43 


\section{Lista de Tabelas}

Tabela 1 - Características gerais do genoma nuclear de $P$. vivax.

pg. 14 


\section{SUMÁRIO}

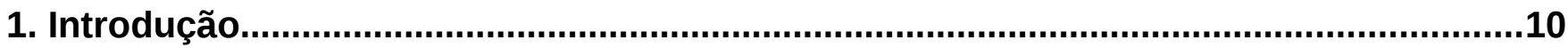

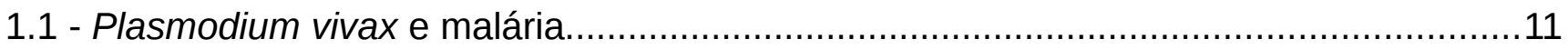

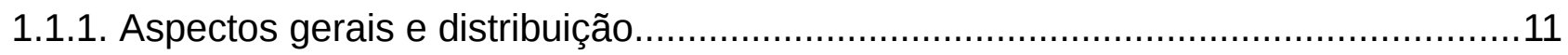

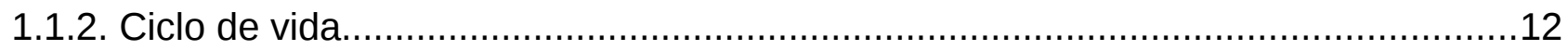

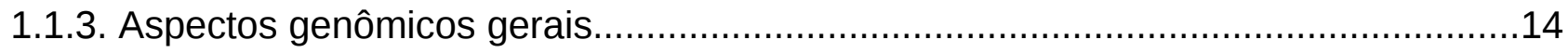

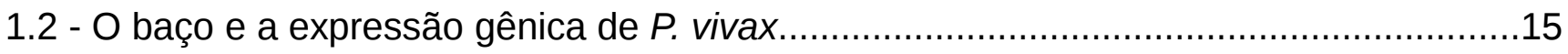

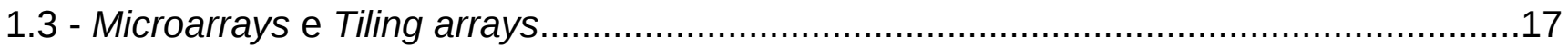

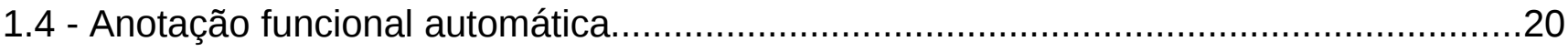

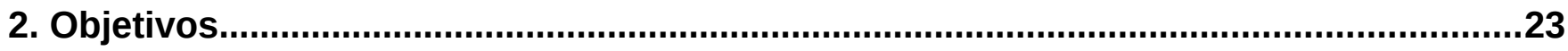

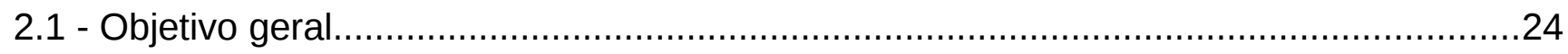

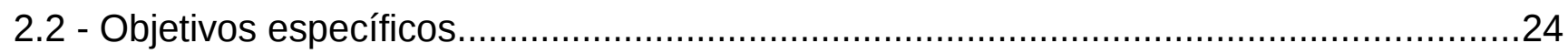

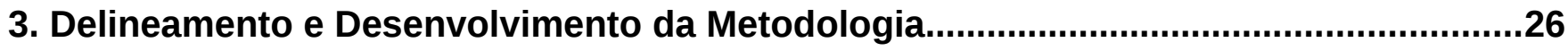

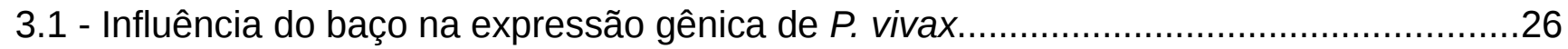

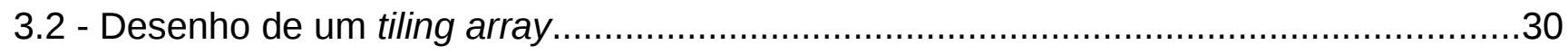

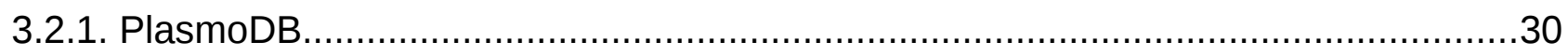

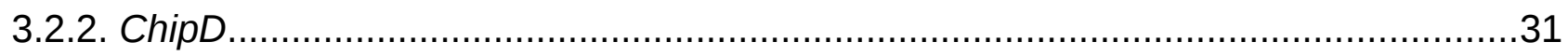

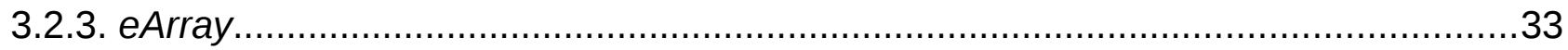

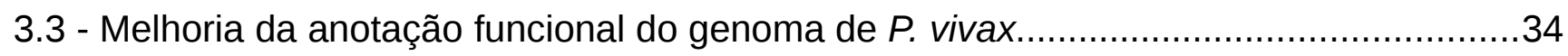






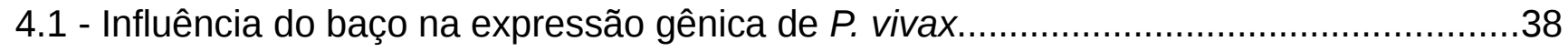

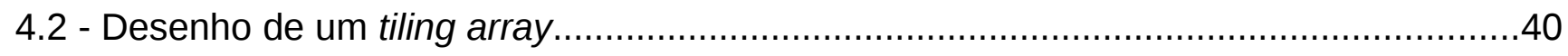

4.3 - Melhoria da anotação funcional do genoma de $P$. vivax............................................ 41

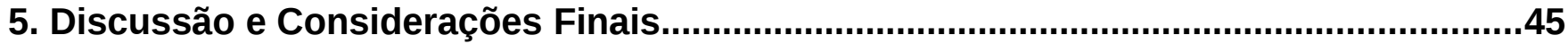

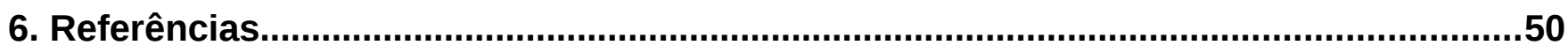




\section{INTRODUÇÃo}




\section{$1.1 \quad$ Plasmodium vivax e malária}

\subsubsection{Aspectos gerais e distribuição}

Plasmodium vivax é um dos parasitas responsáveis por causar malária em seres humanos. Apresenta a maior distribuição global (Figura 1) em comparação às outras espécies do gênero Plasmodium, havendo 2,85 bilhões de pessoas no planeta sob áreas de risco de infecção (Guerra et al., 2010). No Brasil, segundo dados do Ministério da Saúde (http://portal.saude.gov.br/), são registrados mais de 300 mil casos de malária por ano, 85\% deles causados por $P$. vivax, concentrados em sua maioria na região Amazônica (Pereira et al., 2011).

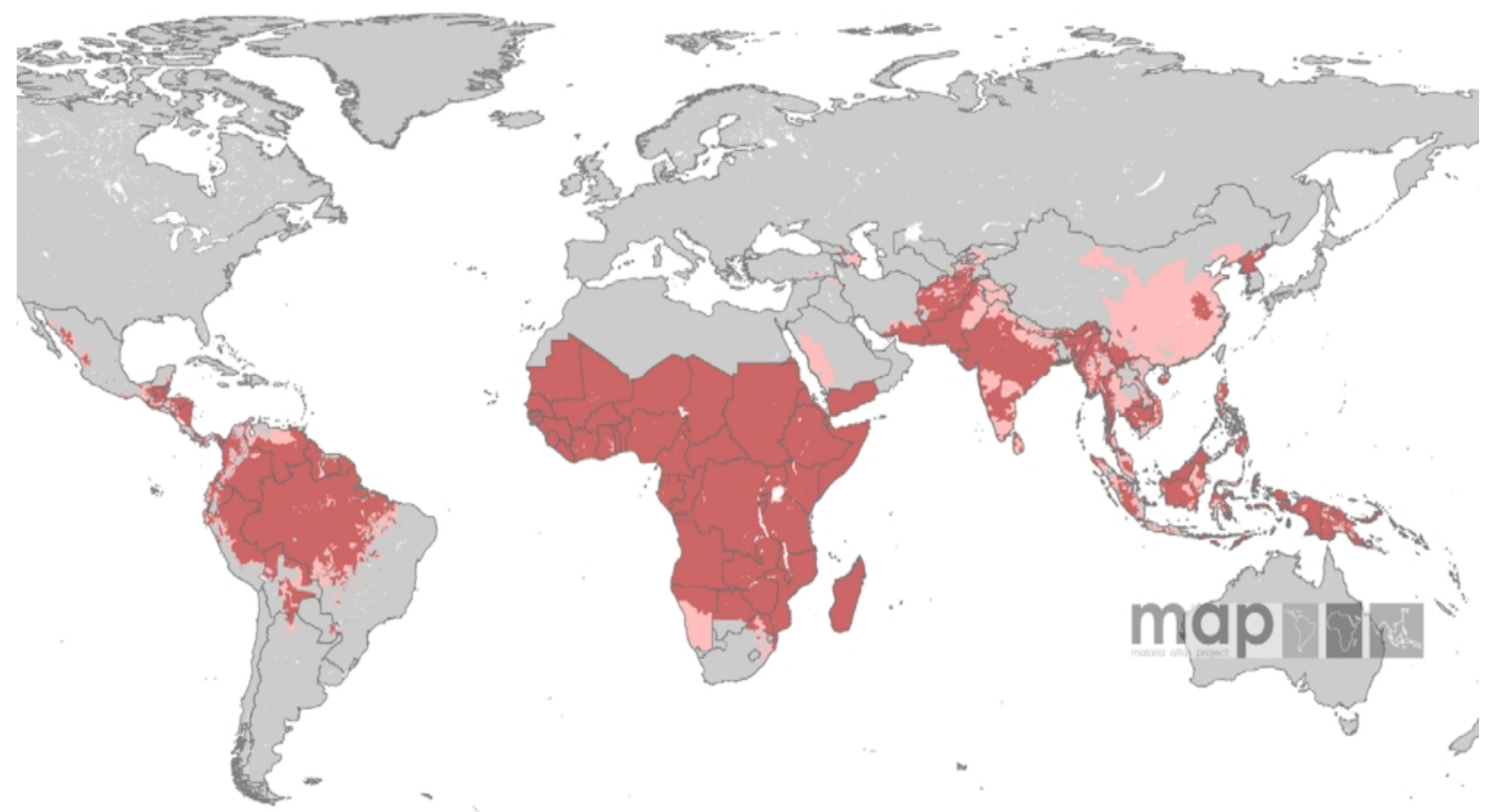

Figura 1 - Mapa do risco de malária por infecção de $P$. vivax - estimativa inicial. A coloração foi aplicada conforme a incidência anual de P. vivax no local (PVAPI). As áreas em vermelho foram definidas como "estáveis" (com PVAPI $\geq 0,1$ por 1.000 pessoas por ano), com risco constante e permanente. As áreas em rosa como "instáveis" (PvAPI < 0,1 por 1.000 pessoas por ano) e as áreas em cinza como "sem risco". Fonte: Guerra et al., 2010.

Apesar de sua ampla distribuição, o estudo desse parasita é muitas vezes negligenciado em relação a $P$. falciparum, causador da malária humana do tipo letal. Isso 
se deve principalmente ao fato de que o cultivo contínuo in vitro de $P$. vivax é limitado (Udomsangpetch et al., 2008; Carlton et al., 2011) e por esse parasita ser considerado gerador de uma forma de malária com menor gravidade. Porém, sua infecção muitas vezes pode afetar de diferentes formas órgãos como baço, fígado, rins, pulmões, cérebro, causando severos sintomas e síndromes clínicas graves, e, segundo publicações recentes, até mesmo levar à morte (Barcus et al., 2007; Price et al., 2007; Genton et al., 2008; Tjitra et al., 2008; Anstey et al., 2009; Kochar et al., 2009; Parakh et al., 2009; Bassat et al., 2011; Singh et al., 2011).

Além do evidente interesse biomédico relacionado à malária, existem também questões biológicas intrigantes a respeito de aspectos únicos de $P$. vivax, como a formação e metabolismo de seus diferentes estágios de vida, mecanismos de invasão celular, estratégias de escape do sistema imune do hospedeiro, entre outras, que necessitam ser investigadas para uma maior compreensão da biologia singular desse parasita (Mueller et al., 2009).

\subsubsection{Ciclo de vida}

O ciclo de vida de P. vivax (Figura 2) compreende uma fase sexuada, que ocorre em mosquitos do gênero Anopheles, e uma fase assexuada em hospedeiros humanos. $O$ inseto vetor inocula de 15 a 200 parasitas na corrente sanguínea do hospedeiro, no estágio de esporozoítos, formas infectantes extracelulares do plasmódio. Essas formas permanecem durante alguns minutos na corrente sanguínea do hospedeiro e em seguida invadem os hepatócitos. Multiplicam-se então por reprodução assexuada através do processo de esquizogonia, originando os esquizontes, que posteriormente se diferenciam em milhares de merozoítos hepáticos. O desenvolvimento nas células do fígado dura cerca de uma semana. Após esse período, os hepatócitos são rompidos e os merozoítos liberados na corrente sanguínea do hospedeiro, na forma de merossomas, onde posteriormente irão penetrar as hemácias.

Os parasitas se desenvolvem nas hemácias, diferenciam-se em trofozoítos que se reproduzem por esquizogonia, formando os esquizontes, os quais provocam o rompimento das hemácias, liberando mais merozoítos na corrente sanguínea, que irão invadir outras hemácias. Nas infecções por $P$. vivax, o mosquito vetor inocula populações geneticamente distintas de esporozoítos. Algumas delas se desenvolvem rapidamente enquanto outras ficam em estado de latência nos hepatócitos, denominadas hipnozoítos, 
responsáveis pelas recaídas tardias da doença. No caso de $P$. vivax, preferencialmente hemácias imaturas, chamadas de reticulócitos, são infectadas (Kitchen, 1938).

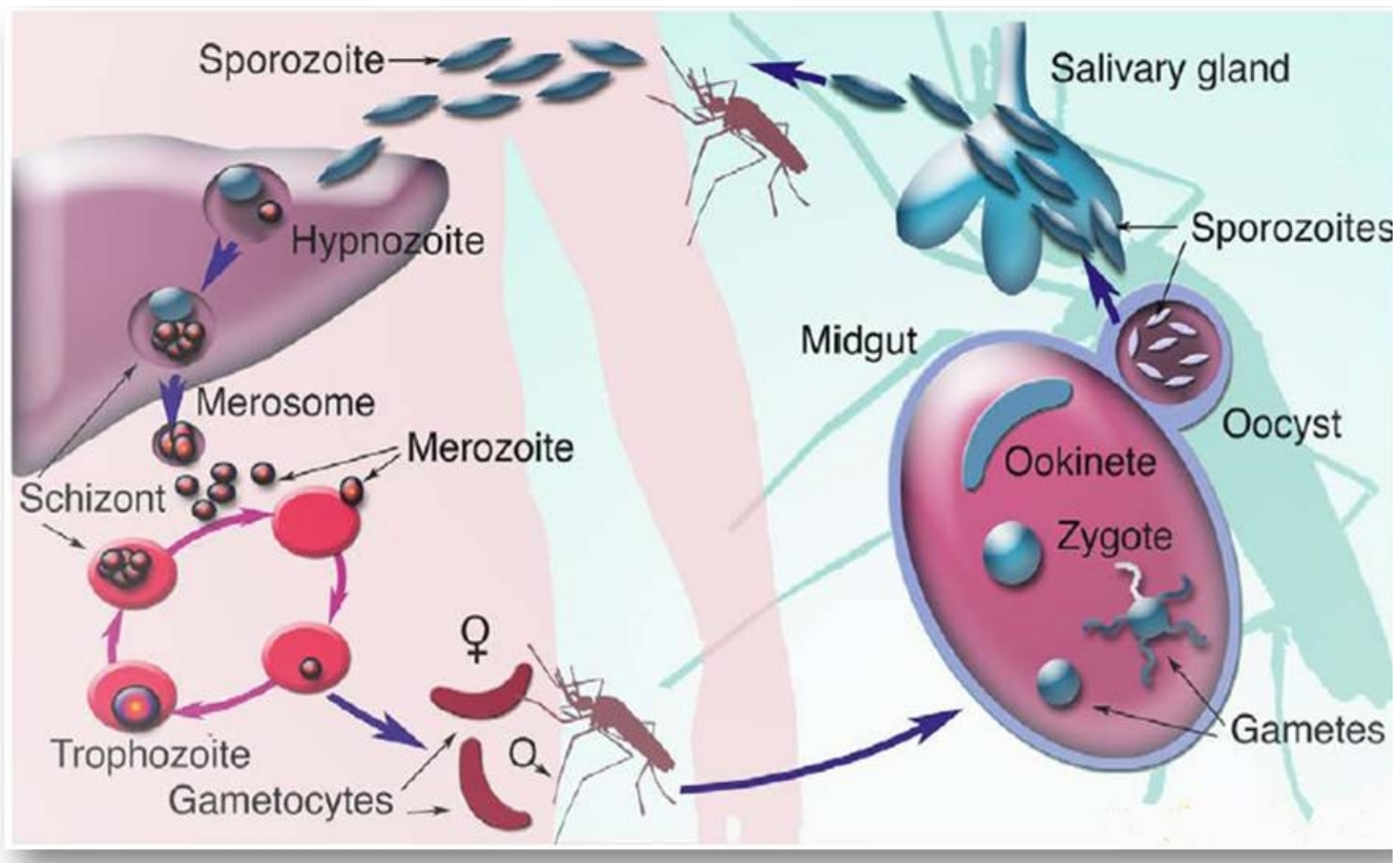

Figura 2 - Ciclo de vida de $P$. vivax no hospedeiro humano e no mosquito vetor. Fonte: Modificado de Westemberger et al., 2010.

Após algumas gerações de reprodução assexuada, ocorre a diferenciação em estágios sexuados, os gametócitos, que seguirão seu desenvolvimento no mosquito. Os gametócitos se desenvolvem dando origem ao macrogameta feminino e a oito microgametas masculinos, através do processo de exflagelação.

No vetor, ocorre a fecundação, formando o zigoto que se desenvolve e origina o oocineto. Esse oocineto atinge a parede do intestino médio do mosquito, onde se encista, passando a ser chamado de oocisto. Nesse local, ele sofre divisões e, dentro de alguns dias, o cisto se rompe e os esporozoítos são liberados. Eles são disseminados por todo o corpo do inseto pela hemolinfa e atingem as glândulas salivares. A partir daí, o inseto, ao picar um ser humano, injeta os esporozoítos no hospedeiro, reiniciando o ciclo de vida do parasita. 


\subsubsection{Aspectos genômicos gerais}

Em 2008, Carlton e colaboradores publicaram os resultados do sequenciamento do genoma nuclear da linhagem "Salvador I" de $P$. vivax e realizaram também um estudo comparativo com outras espécies do gênero Plasmodium. Um resumo das principais características genômicas de $P$. vivax pode ser visto na Tabela 1.

Tabela 1 - Características gerais do genoma nuclear de $P$. vivax

\begin{tabular}{ll}
\hline Característica & $P$. vivax \\
\hline Genoma & \\
\hline Tamanho (Mb) & 26,8 \\
\hline Número de cromossomos & 14 \\
\hline Cobertura (fold) & 10 \\
\hline Conteúdo G+C (\%) & 42,3 \\
\hline Genes & \\
\hline Número de genes & $5.433^{*}$ \\
\hline Tamanho médio dos genes** & $2.164^{* * *}$ \\
\hline Densidade dos genes (pb por gene) & $4.462,9^{* * *}$ \\
\hline Porcentagem codificante ${ }^{* *}$ & $48.5^{* * *}$ \\
\hline Genes com íntrons (\%) & $52,1^{* * *}$ \\
\hline Éxons & $2,5^{* * *}$ \\
\hline Número médio por gene & $46,5^{* * *}$ \\
\hline Conteúdo G+C (\%) & $957^{* * *}$ \\
\hline Tamanho médio (pb) & $48,8^{* * *}$ \\
\hline Íntrons & $192^{* * *}$ \\
\hline Conteúdo G+C (\%) & $42,5^{* * *}$ \\
\hline Tamanho médio (pb) & $1.994^{* * *}$ \\
\hline Regióes intergênicas & 44 \\
\hline Conteúdo G+C (\%) & 3 \\
\hline Tamanho médio (pb) & 7 \\
\hline RNAs & \\
\hline Número de genes de tRNA & \\
\hline Número de genes de rRNA 5S & \\
\hline Número de genes de rRNA 5.8S/18S/28S & \\
\hline Incluindo pseudogenes e genes parciais, excluindo genes de RNAs não-codificantes \\
Fonte: Modificado de Carlton et al., 2008.
\end{tabular}

O resultado desse esforço internacional está disponível para toda a comunidade científica no GenBank (http://ncbi.nlm.nih.gov/genbank), sob o número de acesso AAKM00000000 e no banco de dados PlasmoDB (Aurrecoechea et al., 2009; http://plasmodb.org). 
O parasita apresenta 14 cromossomos haplóides, assim como outras espécies do mesmo gênero, com um genoma de $26,8 \mathrm{Mb}$, cerca de $3 \mathrm{Mb}$ maior que o de $P$. falciparum, diferença essa que corresponde principalmente a regiões não-codificantes. $O$ número de genes de $P$. vivax é bastante semelhante ao de $P$. falciparum. Entre os genes com função conhecida em $P$. falciparum, $82 \%$ estão presentes em $P$. vivax e os outros $18 \%$ são únicos para cada espécie (Das et al., 2009). O conteúdo de A+T (adenina e timina) é a maior diferença observada nos genomas das duas espécies: representa $76,3 \%$ do genoma de $P$. falciparum e $53,5 \%$ de $P$. vivax, além disso, a distribuição das regiões ricas em A+T é limitada às porções subteloméricas em $P$. vivax.

\subsection{O baço e a expressão gênica de $P$. vivax}

O baço é o maior órgão linfóide do corpo humano, rico em células do sistema imune, capaz de produzir, controlar e armazenar células sanguíneas, além de eliminar células vermelhas anormais, partículas presentes no sangue e agentes infecciosos, como os parasitas causadores da malária (Mebius et al., 2005; Porto et al., 2010).

A malária é capaz de induzir alterações estruturais variáveis no baço. A importância desse órgão para o combate da doença foi demonstrada em estudos com humanos, macacos e roedores esplenectomizados (Portillo et al., 2011). Durante os estágios eritrocíticos, em que os parasitas causadores da malária estão dentro das hemácias, o baço é o principal órgão responsável pela defesa do organismo e eliminação das células infectadas (Engwerda et al., 2005), destruindo os parasitas e modulando a expressão dos antígenos de P. vivax expressos nessas células (Bachmann et al., 2009).

O grupo de pesquisa liderado pelo parasitologista molecular Dr. Hernando del Portillo do Centro Internacional de Saúde de Barcelona - CRESIB, colaborador do presente projeto, identificou um grupo de genes, denominados genes da família vir (Portillo et al., 2001), que teriam papel fundamental no escape do parasita do sistema imune do hospedeiro (Fernandez-Becerra et al., 2009). A família vir é composta por 346 genes, com diferentes números de éxons, variando de 1 a 5 , e com tamanhos entre 156 a 3434 pares de bases (Carlton et al., 2008). Essa família gênica é dividida em diferentes sub-famílias e contém genes que podem gerar produtos que apresentam diferentes localizações sub-celulares (Bernabeu et al., 2011) e potencialmente participar de funções como variação antigênica (Portillo et al., 2001), citoaderência ao baço (Portillo et al., 2004), aderência aos pulmões (Anstey et al., 2009) e aderência de reticulócitos infectados 
a receptores de células endoteliais in vitro (Carvalho et al., 2010).

Uma questão que ainda não foi completamente solucionada é como $P$. vivax é capaz de escapar da eliminação através do baço, podendo assim estabelecer infecções crônicas. Com base em análises da estrutura e função desse órgão durante a malária, além da expressão de variantes gênicas geradoras das proteínas VIR, foi proposta uma hipótese para explicar o mecanismo de escape (Figura 3).

No lado esquerdo da Figura 3, é apresentada a circulação aberta normal em que o baço libera sangue na malha reticular, onde os reticulócitos infectados por $P$. vivax são destruídos por macrófagos. No lado direito, o modelo proposto é apresentado, no qual a patologia induz mudanças na arquitetura do baço. Os reticulócitos infectados por $P$. vivax, induzem a formação de uma barreira celular nesse órgão, resultado da proliferação de fibroblastos. Esses reticulócitos infectados citoaderem à barreira celular através de proteínas VIR (e/ou outros ligantes até então desconhecidos), ficando fisicamente protegidos e escapando assim da eliminação dos macrófagos presentes no baço (Portillo et al., 2004; Fernandez-Becerra et al., 2009).

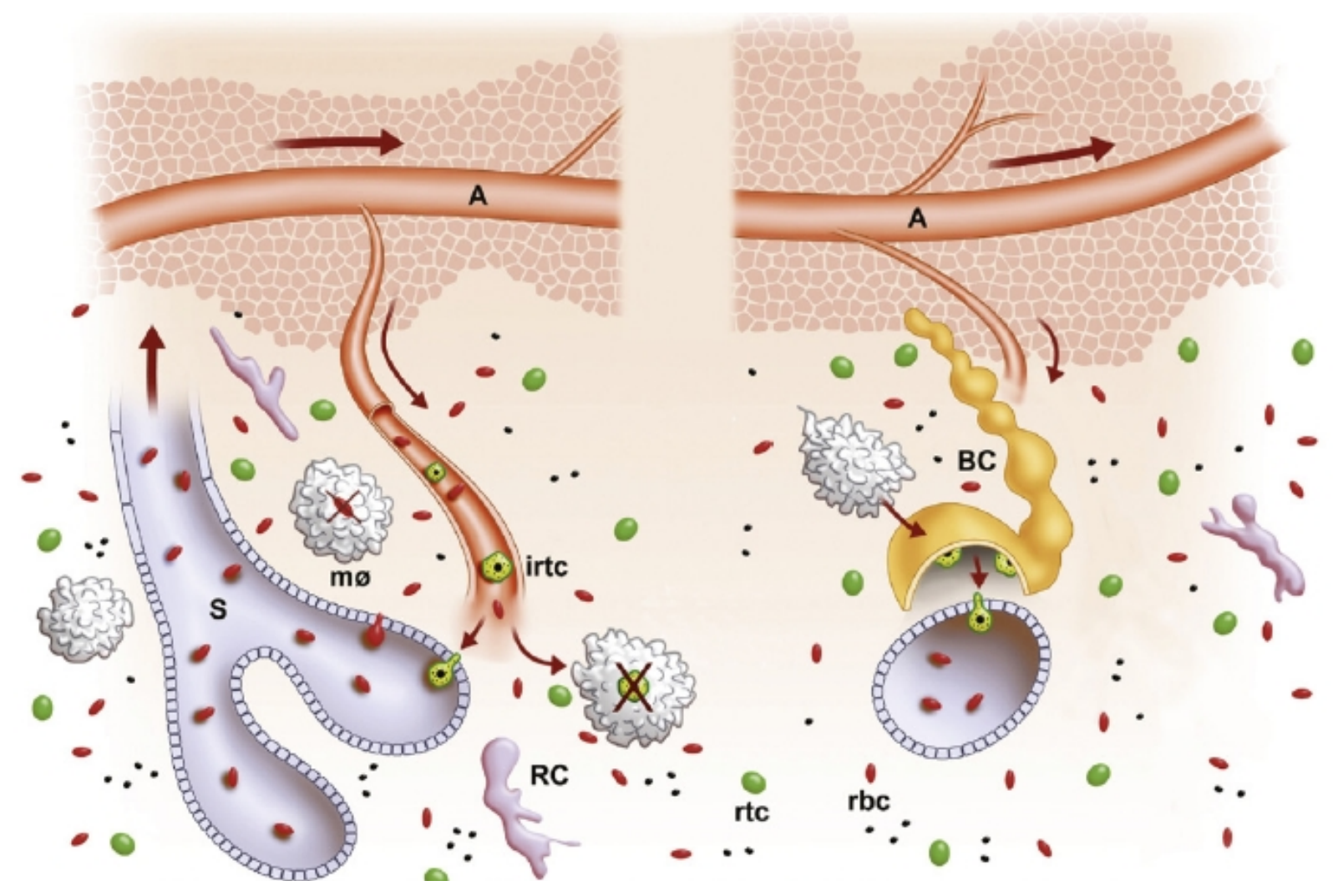

Figura 3 - Modelo de escape do parasita da eliminação pelo baço. Abreviaturas: A, artéria; S, lúmen do seio venoso; RC, células reticulares; rtc, reticulócitos; rbc, glóbulos vermelhos; irtc, reticulócitos infectados; m $\varnothing$, macrófagos; BC, barreira celular. Fonte: Fernandez-Becerra et al., 2009. 
Um estudo recente realizado em camundongos infectados com linhagens distintas de P. yoelli, apresenta resultados que suportam a formação dessa barreira celular no baço de hospedeiros infectados com uma linhagem que causa malária não-letal (Martin-Jaular et al., 2011), assim como geralmente ocorre nas infecções por P. vivax. Entretanto, para que essa hipótese seja confirmada também em $P$. vivax, são necessárias mais investigações. É no contexto desta importante pergunta científica que o presente trabalho se insere.

\section{$1.3 \quad$ Microarrays e Tiling arrays}

Os microarranjos de DNA, conhecidos como microarrays, são amplamente utilizados em estudos de expressão gênica há vários anos. Nesse tipo de experimento, são selecionados genes de interesse e, a partir de sua sequência, são desenhadas uma ou mais sondas, também chamadas de probes, moléculas de DNA de fita simples que servem como detectores da expressão de um determinado gene. Essas sondas são imobilizadas em lâminas de vidro (ou chips), contendo milhares de spots, onde cada grupo de sondas com uma mesma sequência é fixado.

Para a realização do experimento, geralmente é feita a extração de RNA das amostras de interesse e essas moléculas são convertidas em cDNA, através de transcrição reversa, devido à sua maior estabilidade. Para a síntese do cDNA, são utilizados nucleotídeos modificados, contendo fluoróforos (como Су3 e Сy5), para possibilitar a futura detecção.

As moléculas de cDNA geradas são hibridizadas com as sondas da lâmina que se ligam a determinadas probes por complementaridade. Nos microarrays ditos de duas cores, duas populações distintas de cDNA, originadas de amostras diferentes, são marcadas com fluoróforos distintos e são hibridizadas ao mesmo tempo na lâmina, ou seja, competitivamente. Após a hibridização, ocorre a excitação dos fluoróforos por um laser, a lâmina é escaneada e a intensidade de fluorescência do material é medida. Uma visão geral das etapas para a realização de um experimento utilizando um microarray de duas cores é apresentada na Figura 4. 


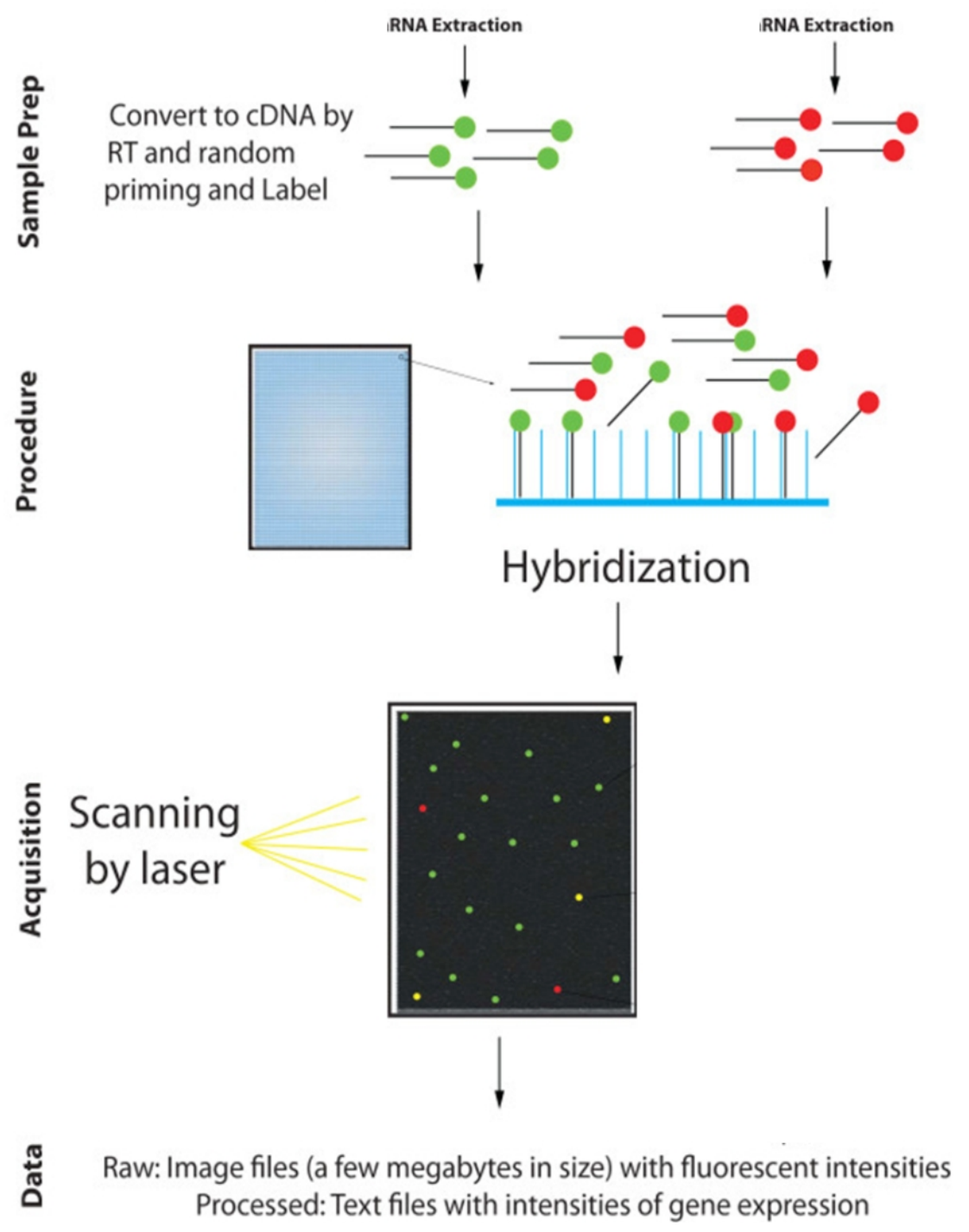

Figura 4 - Visão geral de um experimento de microarray. Fonte: Modificado de Malone et al., 2011.

A razão da intensidade entre as duas populações hibridizadas é utilizada como uma medida de abundância relativa da quantidade de moléculas de RNA presentes nas amostras iniciais. Assim, essa razão de hibridização entre as amostras representaria a sua razão de expressão gênica, podendo ser utilizada para a comparação da expressão entre duas condições biológicas de interesse, com a identificação de genes expressos e não-expressos, além de genes diferencialmente expressos nas duas diferentes condições.

Análises do transcritoma de $P$. vivax utilizando a técnica de microarray já foram realizadas anteriormente, indicando que esse tipo de metodologia também é eficaz no estudo de diversos aspectos da biologia desse parasita (Bozdech et al., 2008; Dharia et al., 2010). 
Uma variação mais recente da tecnologia de microarrays são os chamados tiling arrays, considerados poderosos instrumentos de investigação em escala genômica (Mockler et al., 2005). Essa técnica possui os mesmos princípios básicos de um experimento de microarray, apenas difere na natureza dos fragmentos genômicos investigados, as sondas (Royce et al., 2005; Ji \& Wong, 2005; Liu, 2007). No caso do tiling array, as sondas são desenhadas de modo a cobrirem toda a extensão de um dado gene, de uma região do genoma, ou até mesmo do genoma inteiro de um organismo, com ou sem intervalos. As sondas desenhadas podem apresentar sobreposição ("overlapping") ou não ("end-to-end" ou "average spacing"), conforme a Figura 5, sendo que, quanto maior a sobreposição existente entre essas sondas, maior será a resolução do experimento.

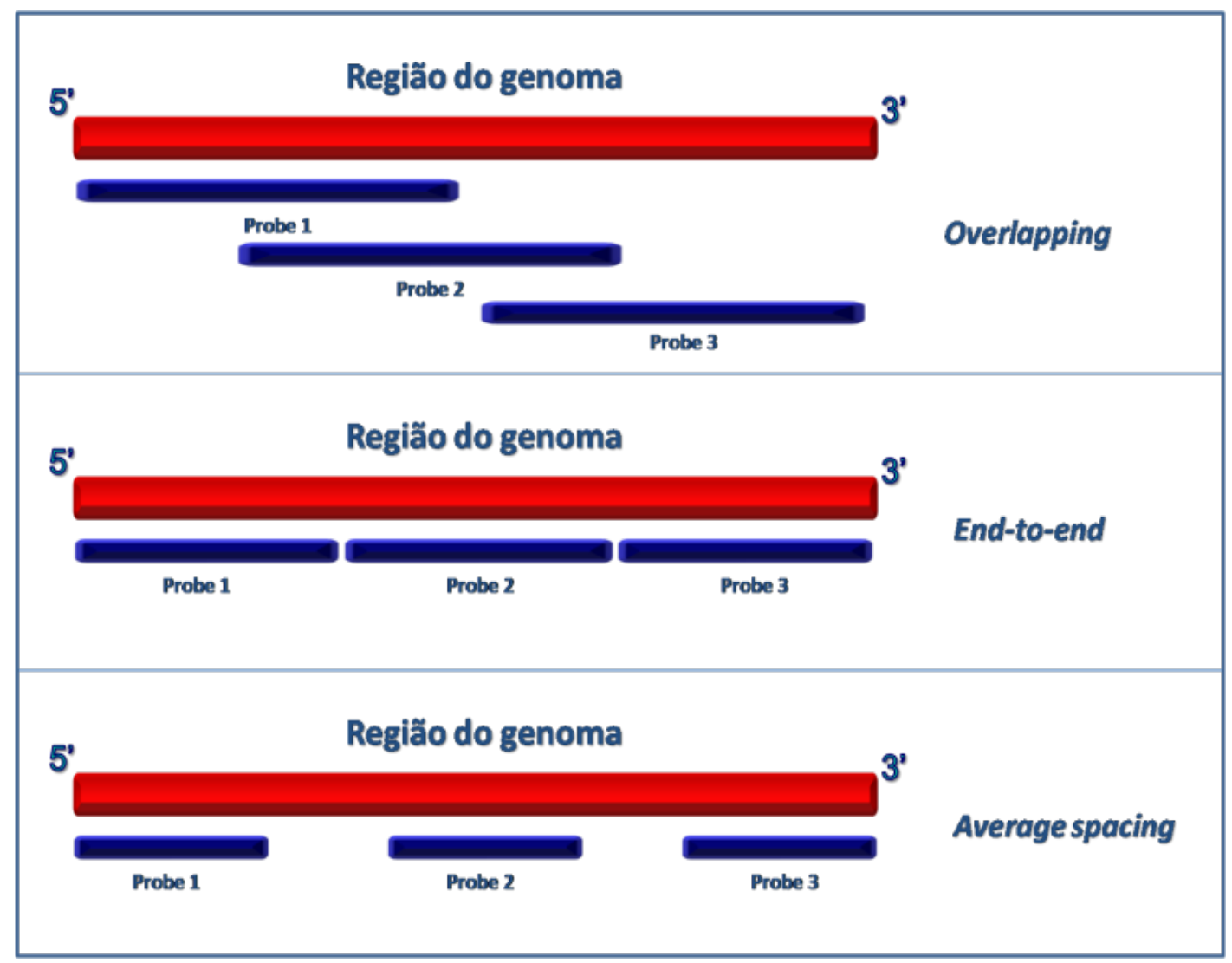

Figura 5 - Tipos de design de sondas de tiling array de acordo com o seu espaçamento.

A partir dessa técnica é possível, além de mensurar expressão gênica, realizar anotação experimental de genomas, determinar a estrutura dos transcritos de genes, estudar fatores de transcrição em redes de regulação gênica, encontrar elementos ainda 
não descritos do genoma, como novas sequências transcritas, elementos regulatórios, entre outros. Outra aplicação comum é o estudo de regiões promotoras e fatores de transcrição, por meio da técnica denominada ChIP-chip, em que um ensaio de imunoprecipitação da cromatina $(C h I P)$ é acoplado à hibridização em um chip de tiling array (Bulyk, 2006; Jiang \& Pugh, 2009; Lei et al., 2010; Lindeman et al., 2010; Xie et al., 2011).

Experimentos utilizando tiling array, combinados com métodos computacionais de análise podem contribuir para a compreensão de processos moleculares e celulares presentes nos organismos vivos. Para determinar e localizar as sequências de interesse, além de processá-las para a produção da lâmina, são necessários o desenvolvimento e aplicação de diversas metodologias de bioinformática, visto que o planejamento é uma etapa fundamental para garantir a qualidade do tiling array e permitir sua aplicação de forma correta.

\subsection{Anotação funcional automática}

Atualmente, com a existência de métodos de sequenciamento em larga escala e com a redução exponencial dos custos para essa tarefa (Figura 6), a velocidade com que as sequências são geradas é muitas vezes superior à da caracterização funcional dos produtos gênicos (Koonin, 2000; Thornton, 2001). Isso torna fundamental o desenvolvimento e aplicação de metodologias com a abordagem in silico para possibilitar a realização de anotação funcional automática de genomas.

Há uma série de metodologias automáticas de anotação funcional, que podem ser classificadas em dois grandes grupos: as abordagens de transferência e as de classificação (Saraç et al., 2010).

Nas abordagens de transferência, de maneira geral, as sequências de interesse são utilizadas para realizar buscas em bancos de dados contendo outras sequências já anotadas, em seguida é calculado um determinado escore de similaridade e a anotação da sequência com maior pontuação de similaridade encontrada no banco de dados é transferida para a sequência alvo. A complexidade e diferenças entre metodologias desse tipo estão associadas à forma como esse escore é calculado por cada uma das diferentes abordagens.

Já os métodos de classificação são baseados em técnicas utilizadas na área de aprendizado de máquinas, como redes neurais, SVM (Support Vector Machines), redes 
bayesianas, entre outras metodologias. Nesse segundo tipo de abordagem, são utilizadas amostras de treinamento positivas e negativas para determinar uma fronteira de classificação que, dada uma sequência de interesse a ser anotada, define se determinada anotação é falsa ou verdadeira para essa sequência. Essas metodologias ainda são pouco difundidas para a realização de anotação funcional automática, mas recentemente sua aplicação tem se tornado cada vez mais frequente na análise de problemas biológicos, pois possuem um melhor desempenho em termos de acurácia de predição em diferentes casos, pelo fato de serem utilizados dados positivos e negativos para 0 treinamento dos classificadores (Leslie et al., 2004; Saraç et al., 2010).

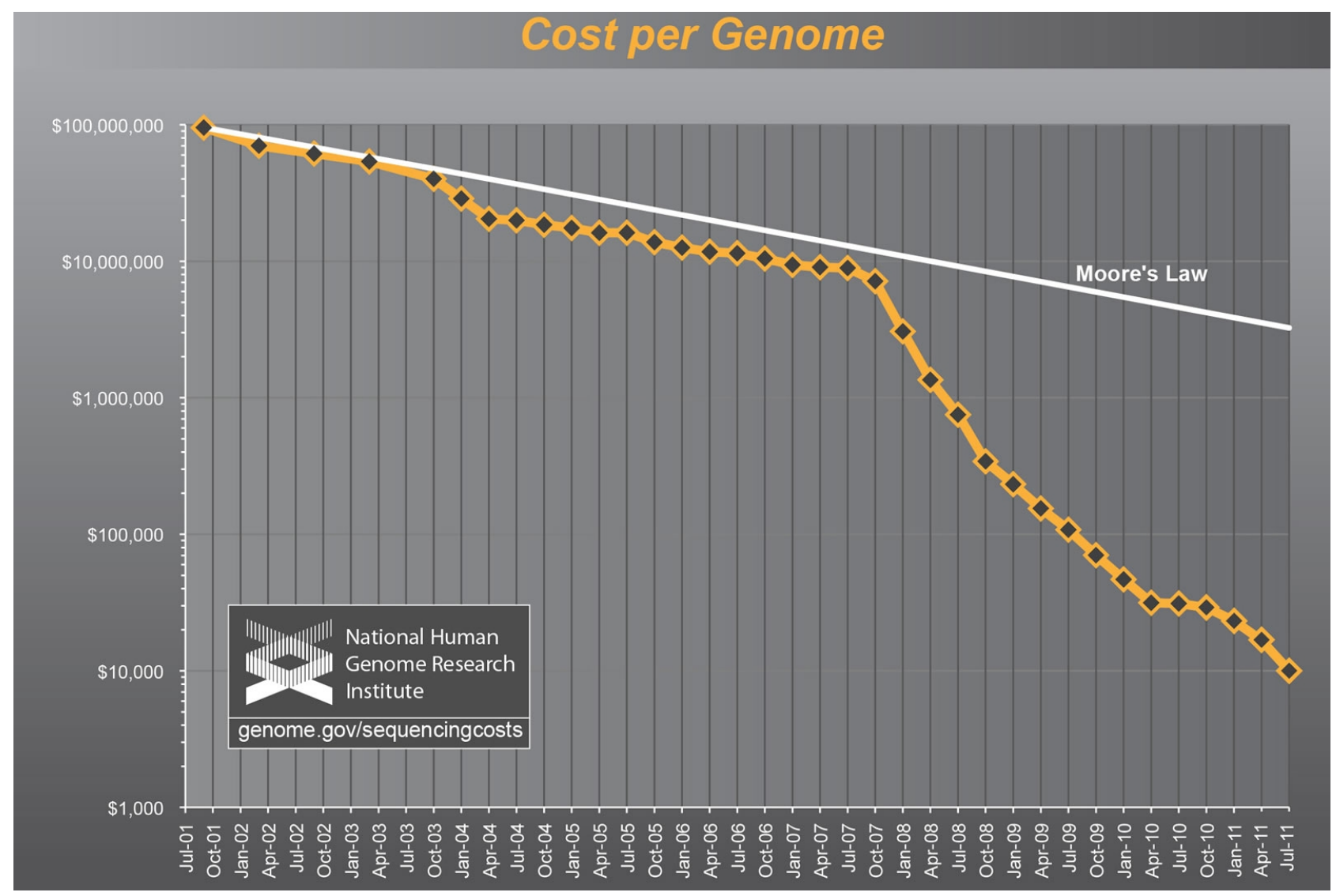

Figura 6 - Redução dos custos de sequenciamento de genomas ao longo dos anos. Fonte: http://www.genome.gov/.

Um recurso importante para realizar anotação funcional automática é o Gene Ontology (GO - http://www.geneontology.org/). O GO é um vocabulário estruturado e controlado de termos, dividido em três ontologias que descrevem aspectos diferentes dos produtos gênicos (Função Molecular, Processo Biológico e Componente Celular) e suas relações. 
Além disso, cada uma das anotações é associada a um ou mais Evidence codes, atributos que fornecem informação sobre como a anotação foi obtida, como por exemplo, experimentalmente, através da literatura, por meio puramente computacional, entre outros, utilizados como uma medida subjetiva de confiabilidade.

Por suas características estruturais e padronização, o GO é atualmente um dos bancos de dados mais utilizados na tarefa de anotação (Plessis et al., 2011). Um exemplo mostrando a estrutura do GO e as relações existentes entre alguns termos é apresentado na Figura 7.

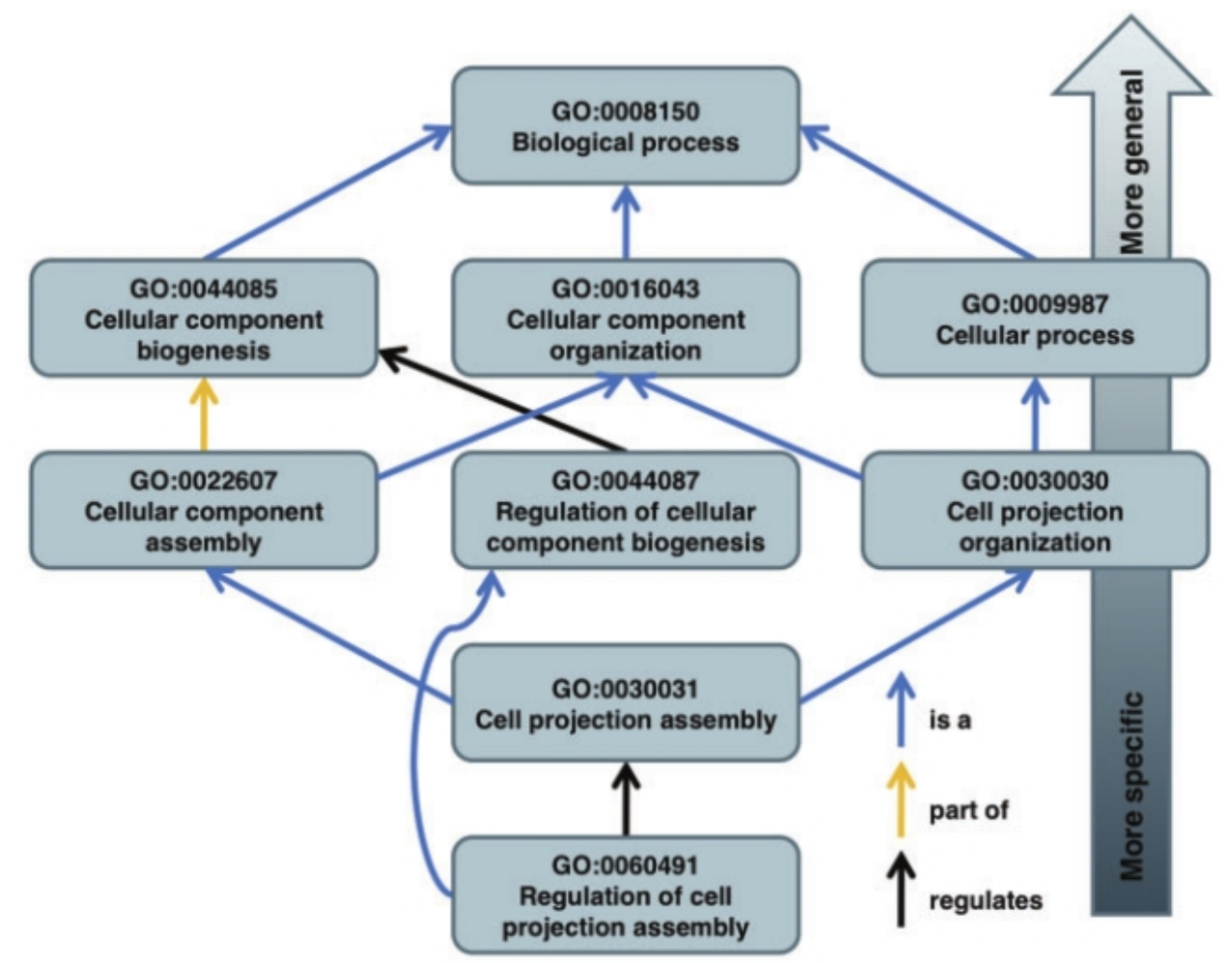

Figura 7 - Representação da estrutura e relações dos termos GO, em que GO:0060491 é o termo mais específico e GO:0008150, o mais genérico. Fonte: Plessis et al., 2011.

No presente estudo, uma das etapas propostas foi a melhoria da anotação existente do genoma de $P$. vivax, através de uma metodologia automática, com objetivo de adicionar informação funcional aos produtos gênicos do parasita e possibilitar uma melhor análise e interpretação biológica dos dados gerados pelos experimentos de transcritômica propostos. 
2. Objetivos 


\section{1 - Objetivo Geral}

Contribuir para o entendimento do mecanismo de escape do processamento do baço do hospedeiro utilizado por Plasmodium vivax, utilizando metodologias de bioinformática, dentro do projeto liderado pelo Dr. Hernando del Portillo.

\section{2 - Objetivos Específicos}

2.2.1 - Investigar a influência do baço na expressão gênica de $P$. vivax através da análise de experimentos de transcritômica utilizando microarrays.

2.2.2 - Projetar um tiling array de $P$. vivax.

2.2.3 - Adicionar informações à anotação do genoma de $P$. vivax através de uma metodologia automática. 
3. Delineamento e Desenvolvimento da Metodologia 


\section{1 - Influência do baço na expressão gênica de $P$. vivax}

A primeira etapa do projeto consistiu na análise de um experimento de transcritômica que havia sido realizado previamente pelo grupo do Dr. Hernando del Portillo. O principal objetivo do estudo foi identificar genes de Plasmodium vivax cuja expressão é dependente da presença do baço do hospedeiro.

$\mathrm{Na}$ fase experimental, realizada pelos colaboradores do CRESIB, foi utilizado o modelo experimental Aotus lemurinus griseimembra, considerado um dos melhores modelos de primatas para estudos relacionados à malária (Herrera et al., 2002). Um macaco dessa espécie foi infectado com a linhagem Salvador-1 de $P$. vivax. Os parasitas foram extraídos e purificados a partir do sangue do animal doador e, posteriormente, utilizados para infectar macacos com baço e macacos sem baço. Após a parasitemia, os parasitas foram retirados do sangue dos hospedeiros e purificados para a posterior a extração de RNA. Esse material foi utilizado para a realização dos experimentos de análise de expressão gênica através de uma plataforma de microarray Agilent $^{\mathrm{TM}}$.

Os dados primários resultantes do microarray foram pré-processados e após essa etapa foi realizada por nosso grupo de pesquisa a identificação dos genes dos parasitas que estavam expressos apenas nos que infectaram macacos com baço, chamados de $S p+2$, através da comparação da expressão gênica dos parasitas extraídos de hospedeiros sem o baço, denominados $S p-1, S p-2$ e $S p-3$. Foram propostos então três modelos probabilísticos para identificar os genes de P. vivax expressos ("ON") nos macacos com baço e não-expressos ("OFF") nos macacos sem baço.

No primeiro modelo, o sinal digital bruto de cada elemento do microarray, proporcional à intensidade de hibridização, foi comparado com o sinal das imediações, regiões chamadas foreground $(F)$ e background $(B)$, respectivamente (Figura 8).

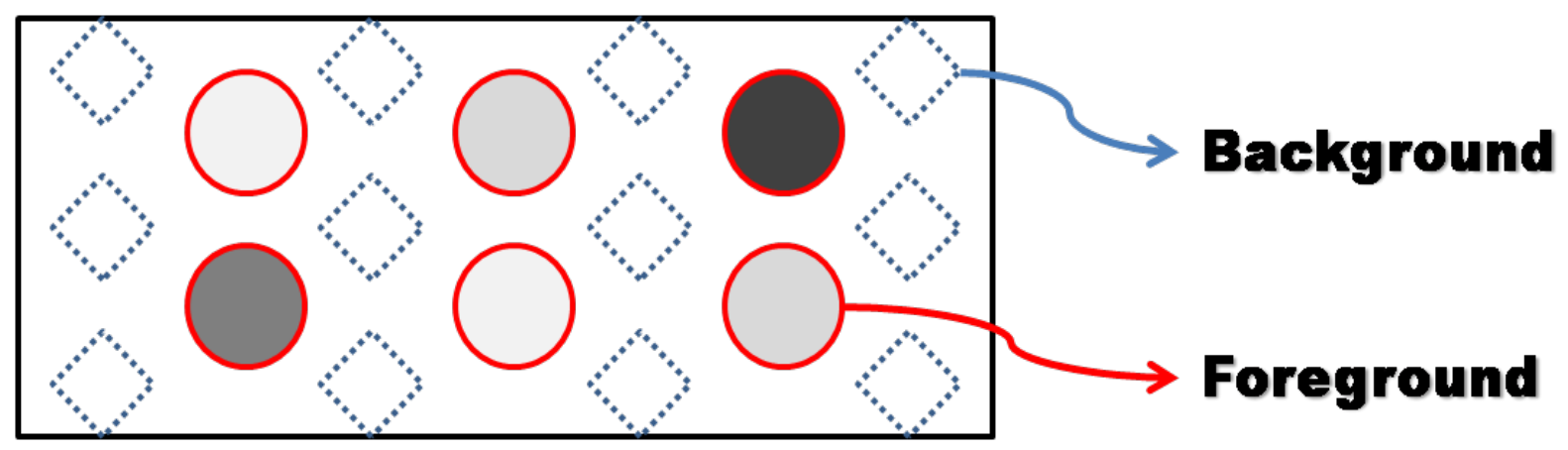

Figura 8 - Representação esquemática das regiões da lâmina de microarray, destacando foreground e background. 
As intensidades das duas regiões foram modeladas como distribuições gaussianas (Figura 9), em que: $F \sim N\left(\mu_{f}, \sigma_{f}^{2}\right)$ e $B \sim \mathrm{N}\left(\mu_{b}, \sigma_{b}^{2}\right)$; onde $\mu_{f}$ e $\mu_{b}$ são a média do foreground e background, respectivamente, e $\sigma_{f}^{2}$ e $\sigma_{b}^{2}$ representam as variâncias.

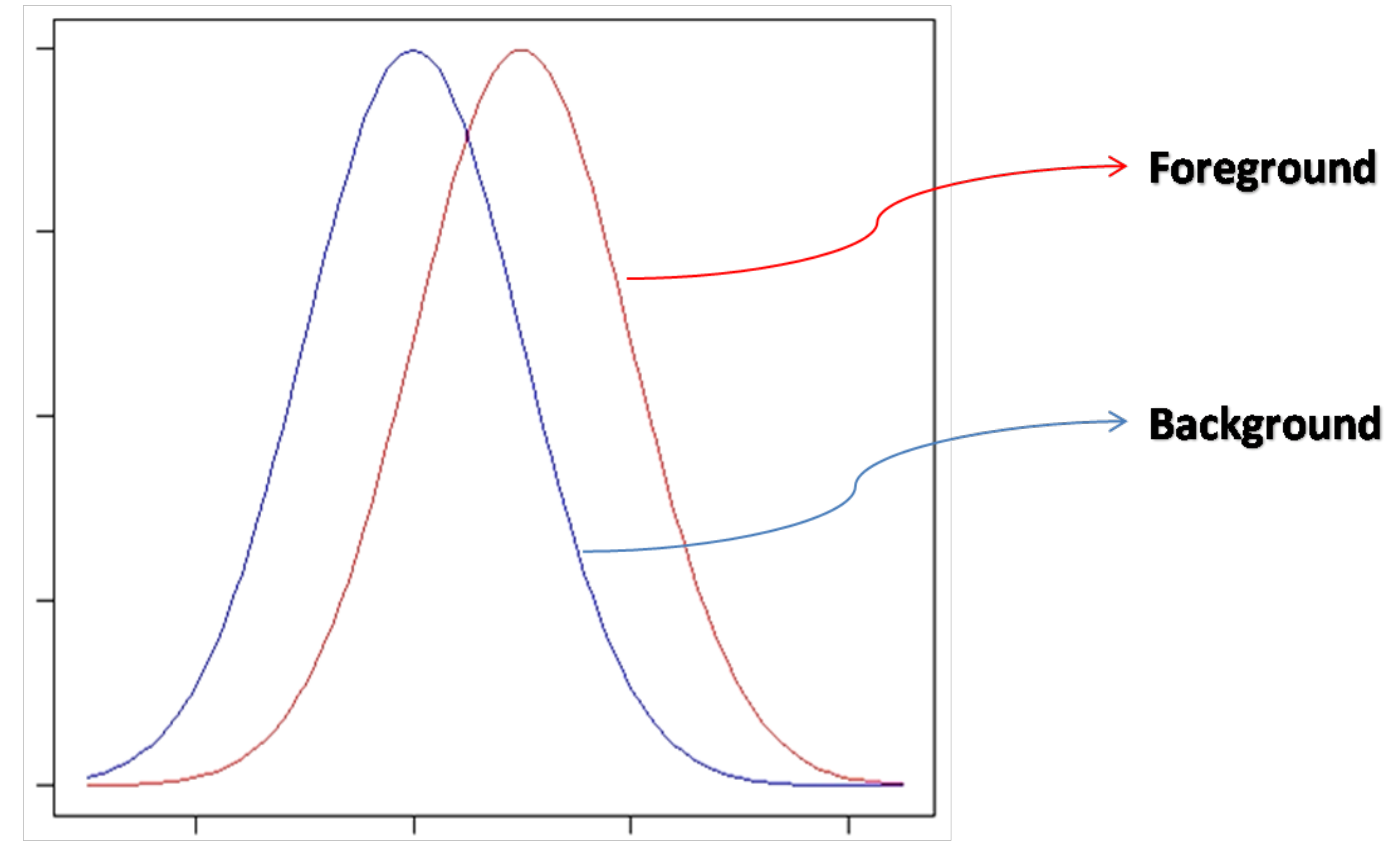

Figura 9 - Representação da modelagem das regiões de foreground e background como distribuições gaussianas.

Através desse modelo, calcula-se a probabilidade $p$ de expressão para os elementos do microarray:

$$
p=\operatorname{Pr}(F>B)
$$

As sequências de interesse são aquelas em que existe sinal de hibridização maior no foreground do que no background em indivíduos com baço e em que, ao mesmo tempo, não existe intensidade relevante, comparada ao background, nos indivíduos esplenectomizados. Ao definir valores de corte para as probabilidades, busca-se os genes que satisfazem tal condição. Foram considerados expressos, os genes que possuíam mais de $90 \%$ de probabilidade de expressão comparados ao background, e nãoexpressos os que apresentaram $p<0,60$.

No segundo método, foi proposta a comparação da intensidade dos spots dos genes com os controles negativos presentes na lâmina. Os controles negativos foram considerados como sendo realizações de uma variável aleatória denominada "Controle Negativo" e sua função densidade de probabilidade foi modelada através do método de 
Kernel Density Estimator. Esse método tem por objetivo estimar empiricamente a função densidade de probabilidade de uma variável aleatória, utilizando as observações dessa variável (Silverman, 1986). É considerada uma técnica model-free por não necessitar que se assuma um modelo prévio. O estimador pode ser escrito da seguinte forma:

$$
\widehat{f}_{h}(x)=\frac{1}{n h} \sum_{i=1}^{n} K\left(\frac{x_{i}-x}{h}\right)
$$

onde $f$ é a função densidade de probabilidade de uma variável aleatória $X, \operatorname{com} x_{1}, x_{2}, \ldots$, $x_{n}$, sendo o conjunto de $n$ observações. O $h$ representa o parâmetro conhecido como bandwidth, e o acento circunflexo sobre o $f$ representa que é um estimador. $K$ é a função kernel utilizada. No caso do estudo, foi utilizada uma função kernel gaussiana.

A média de intensidade de cada spot foi utilizada como um corte e foi calculada a probabilidade da variável "Controle Negativo" estar mais expressa que cada gene (Figura 10). Se essa probabilidade foi menor ou igual a 0,001 , o gene foi considerado "ON", se foi maior que 0,05, "OFF". Os genes de interesse foram os que estavam "OFF" em Sp-1, Sp2 e $S p-3$, e "ON" em $S p+2$.

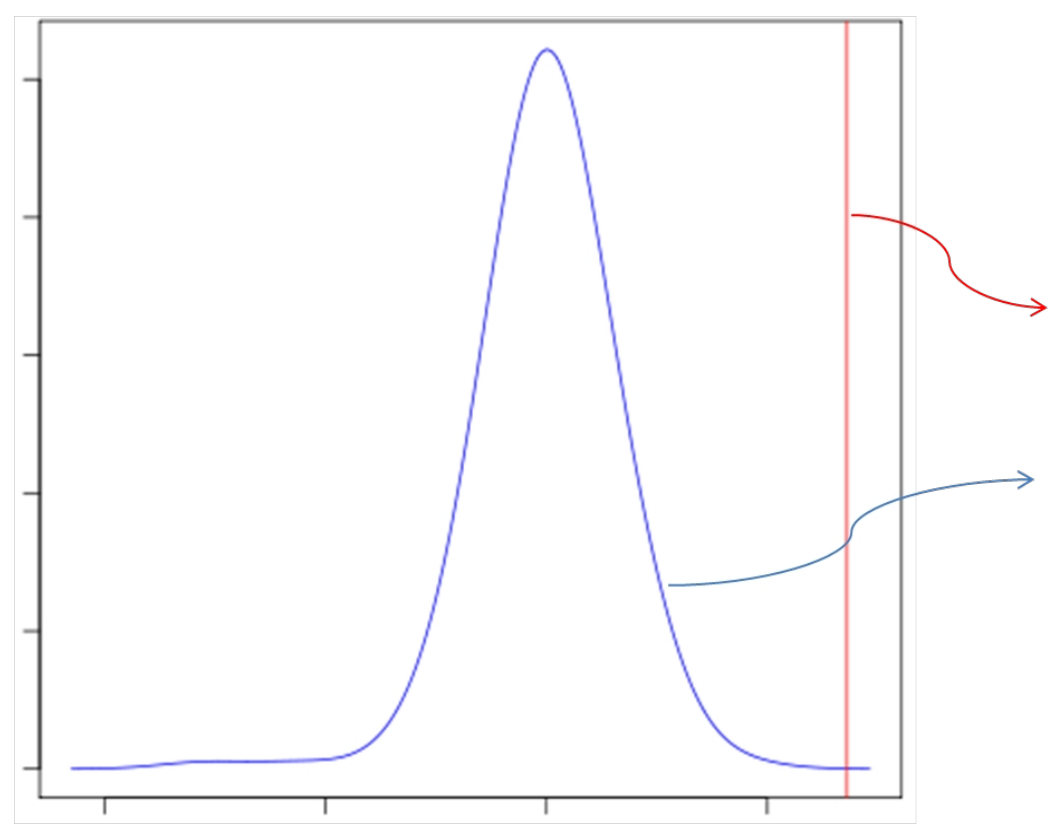

Mean of spot intensity

Probability density function of negative controls

Figura 10 - Representação do segundo modelo de busca por genes expressos e não-expressos, comparando a intensidade de cada spot aos controles negativos. 
No terceiro método proposto, o quantil 0,98 dos controles negativos foi utilizado para criar uma linha de corte. Nessa análise, os genes de interesse foram aqueles em que a média da intensidade era menor que o quantil dos controles negativos em Sp-1, $S p-2$ e $S p-3$, e pelo menos dez vezes maior que o quantil dos controles negativos em Sp+2, conforme a Figura 11.

Os valores de corte das metodologias foram determinados a fim de se realizar análises bastante estringentes, resultando em genes "ON" e "OFF" com diferenças de expressão gênica extremamente acentuadas.



Figura 11 - Representação do padrão de expressão de interesse no terceiro método proposto, em que os controles negativos são utilizados para criar uma linha de corte.

Para a realização de todas as análises e metodologias empregadas nas etapas descritas acima foram desenvolvidos scripts em linguagem de programação $R$ (http://www.r-project.org/) no sistema operacional Ubuntu/Linux. $R$ é uma linguagem de programação e um ambiente de desenvolvimento amplamente utilizado para manipulação de dados e análise estatística em diferentes áreas do conhecimento, incluindo a bioinformática. O software é gratuito, possui código aberto e diversos pacotes disponíveis com as mais variadas funções, podendo ser livremente utilizado e modificado conforme a necessidade do estudo. 
Os três modelos implementados em linguagem $R$ estão livremente disponíveis para download na página web do Laboratório de Processamento de Informação Biológica LabPIB - no seguinte endereço eletrônico: http://labpib.fmrp.usp.br/ bcorrea/analysis-onoff/.

\section{2 - Desenho do tiling array}

\subsubsection{PlasmoDB}

Para o planejamento do tiling array, foram utilizadas sequências do genoma de $P$. vivax do banco de dados PlasmoDB (Aurrecoechea et al., 2009; http://plasmodb.org). Esse banco de dados contém atualmente informações de oito espécies do gênero Plasmodium, entre elas P. vivax. O banco conta também com dados de microarray, RNAseq, experimentos de proteômica, entre outros, para algumas espécies do gênero. Na versão utilizada nessa etapa, 7.1, estão disponíveis 5507 transcritos de $P$. vivax.

O banco de dados oferece a opção de download de quatro tipos de sequência, denominadas de CDS, Protein, Transcript e Genomic. As características de cada um dos tipos de sequência disponíveis são apresentadas na Figura 12.
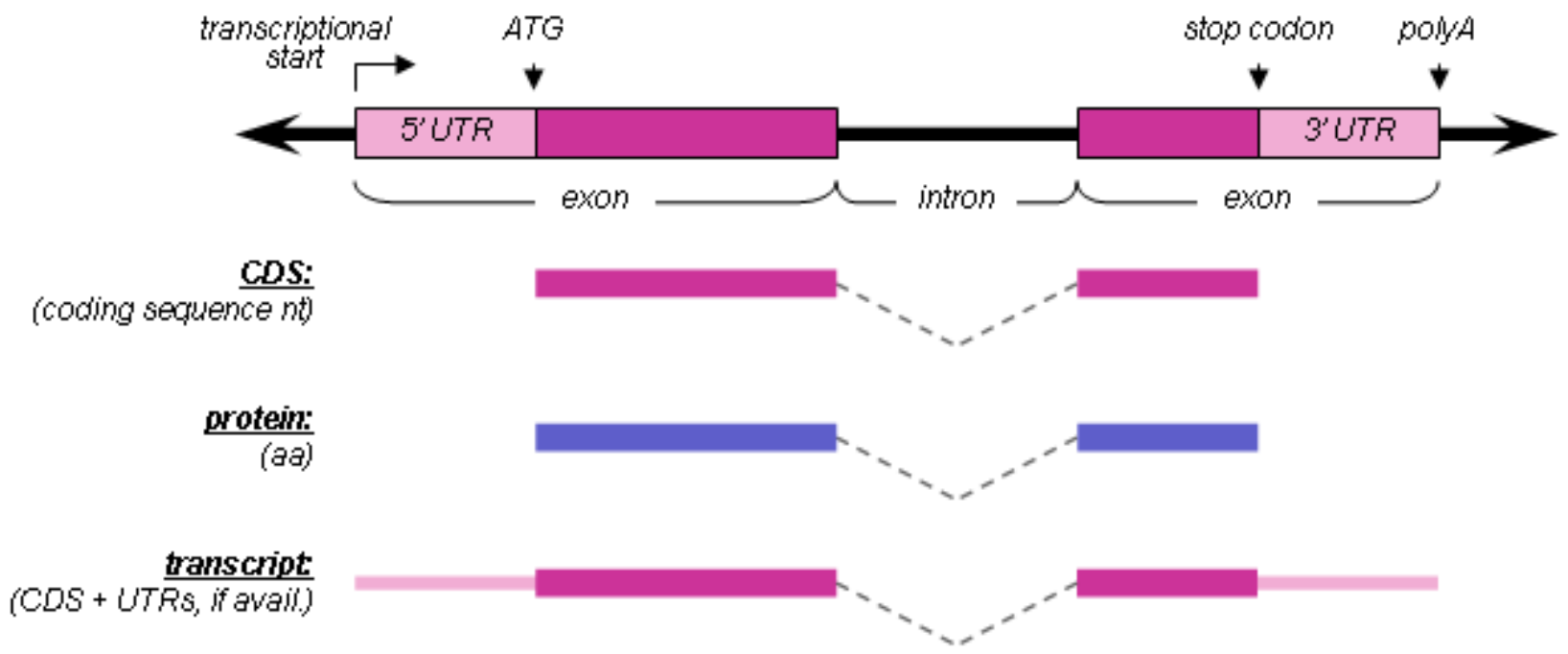

genomic:

(inciudes introns)

Figura 12 - Tipos de sequências disponíveis no banco de dados PlasmoDB. Fonte: http://plasmodb.org. 
Para os objetivos do estudo, identificação de genes do parasita expressos apenas na presença do baço do hospedeiro, foi definido pelos colaboradores que apenas as regiões codificantes seriam de interesse uma vez que, com a tecnologia disponível no momento e pela necessidade de réplicas internas, seria inviável desenhar um tiling array simplesmente cobrindo todo o genoma com probes igualmente espaçadas. Sugerimos então que fossem adicionadas também as regiões 5'UTR e 3'UTR, pela possibilidade de conterem importantes sítios regulatórios, que poderiam fornecer informações valiosas a respeito da regulação da expressão gênica. Dessa forma, o tipo de sequência utilizada para a construção do tiling array foi a Transcript, contendo as regiões 5'UTR, 3'UTR (quando disponíveis) e os éxons de cada gene.

\subsubsection{ChipD}

Existem diversas ferramentas para fazer o desenho das sondas de uma lâmina de microarray, cada uma levando em conta características específicas, com objetivos diversos. A maioria dos algoritmos são focados na escolha de apenas algumas sondas por gene (Chou et al., 2004; Li et al., 2005; Rouillard, 2003; Wernersson \& Nielsen, 2005), o que não se aplica no caso de um tiling array. Algumas ferramentas possibilitam o desenho de sondas para tiling array, porém, em geral, não consideram as características termodinâmicas das sondas desenhadas, fator de grande importância para garantir uma hibridização de qualidade.

Após uma extensa busca e estudo de algoritmos de desenho de sondas para tiling array, como MOID (Zhou \& Abagyan, 2002), TileMap (Ji \& Wong, 2005), MAMMOT (Ryder et al., 2006), ArrayDesign (Gräf et al., 2007), Teolenn (Jourdren et al., 2010), entre outros, foi selecionada a metodologia chipD (Dufour et al., 2010), que tem por objetivo desenhar probes específicas, com propriedades termodinâmicas semelhantes, e garantir uma boa cobertura das sequências alvo.

A ferramenta foi desenvolvida na linguagem de programação JAVA, e fornece ao usuário acesso a um servidor com interface web para o desenho das sondas (Dufour et al., 2010).

Como entrada, a ferramenta recebe as sequências de interesse em formato FASTA. Além disso, o usuário precisa definir uma série de parâmetros como o número máximo de probes no chip, o número de réplicas de cada probe, o ajuste de offset, que define o espaçamento entre as sondas, o modelo para cálculo da temperatura de melting 
(TM), a concentração de íon sódio para o cálculo do modelo, a TM ideal, o tamanho das sondas e o número máximo de ciclos para a síntese das sondas. A ferramenta oferece dois tipos de design: "Genome chip" e "Expression chip". No caso do presente trabalho foi utilizado o "Expression chip" por nossas sequências de interesse serem compostas apenas por regiões transcritas do genoma de $P$. vivax.

As probes são escolhidas através de um sistema de pontuação. Primeiramente, as sequências enviadas são escaneadas e é realizada uma contagem global para cada 15mer dessas sequências. Essa contagem é utilizada para determinar um escore de frequência. Com base no conteúdo das sequências de 15-mer, é calculado independentemente um escore de complexidade. Essas pontuações são combinadas para formar o chamado "uniqueness score", que representa uma medida de especificidade das sequências. Em seguida, é determinada uma sonda candidata para cada posição da sequência fornecida, levando em conta também os parâmetros de entrada e a qualidade da sequência.

Conforme o tamanho definido das sondas, o algoritmo percorre cada posição da sequência de entrada para extrair as probes, até o limite máximo de iterações definido pelo usuário.

O escore final de cada probe é calculado somando três componentes com pesos definidos: a medida de especificidade, a função de TM e a função de tamanho do alvo.

A medida de especificidade é calculada a partir da soma dos escores de "uniqueness" para todas as sequências de 15-mer sobrepostas que formam a sonda, com maior peso para a sequência de 15-mer do centro da sonda.

A função de TM calcula quanto a temperatura predita para cada sonda desvia da ideal, aplicando uma penalidade no escore da probe. Um dos modelos disponíveis é considerado mais eficiente para o cálculo de TM para sondas de tamanho maior ou igual a 50-mer e foi o escolhido para o design por estarem sendo desenhadas sondas de 60mer.

A função de tamanho do alvo aplica penalidades nas sondas com tamanho fora do ideal definido pelo usuário. O algoritmo então seleciona e salva a sonda candidata com maior escore para representar uma determinada posição da sequência.

Por fim, a lista final de probes é selecionada iterativamente. Todas as sondas candidatas são ordenadas conforme seu escore. A probe com maior pontuação de determinada sequência é escolhida e, com base nas restrições de espaçamento fornecidas, as sondas vizinhas são selecionadas ou removidas. Esse processo garante 
uma boa cobertura das sequências alvo, evitando gaps.

Como output, o algoritmo fornece um arquivo contendo uma lista com as sequências das sondas selecionadas, "IDs" identificadores, a posição no genoma, a TM, além do escore final para cada sonda.

\subsection{3. eArray}

A empresa Agilent ${ }^{\mathrm{TM}}$ fornece acesso a uma aplicação web, denominada eArray (https://earray.chem.agilent.com/earray/), que permite fazer o desenho final da lâmina e enviá-la para a fabricação.

Após o projeto das sondas, é possível importá-las para o eArray que permite um desenho personalizado do tiling array. Também podem ser utilizadas sondas préexistentes no banco de dados da empresa Agilent ${ }^{\mathrm{TM}}$, em conjunto com as sondas criadas pelo usuário. Antes de importar as sondas, é necessário um pré-processamento nos arquivos de saída do chipD, para que os formatos sejam compatíveis, realizado através de Shell-script.

Em linhas gerais, o pesquisador elege o tipo de aplicação desejada, nesse caso "Gene Expression", cria um "Probe Group" com as sondas selecionadas, escolhe a capacidade da lâmina a ser produzida (nesse caso, foi encomendada uma lâmina de 1x1M, com capacidade para aproximadamente 1 milhão de spots), define o número de réplicas para as sondas, os controles negativos e positivos, e posteriormente solicita a fabricação da lâmina para a empresa.

É possível também criar um "Grupo de Colaboração", em que pesquisadores de um mesmo grupo podem participar compartilhando informações e auxiliando nas etapas desse processo. A Figura 13 mostra uma visão esquemática do sistema para a criação final do chip, em que é possível utilizar probes já disponíveis no banco de dados da Agilent $^{\mathrm{TM}}$ em conjunto com as desenhadas pelo pesquisador, criar grupos de probes e definir o tipo de lâmina desejada. 


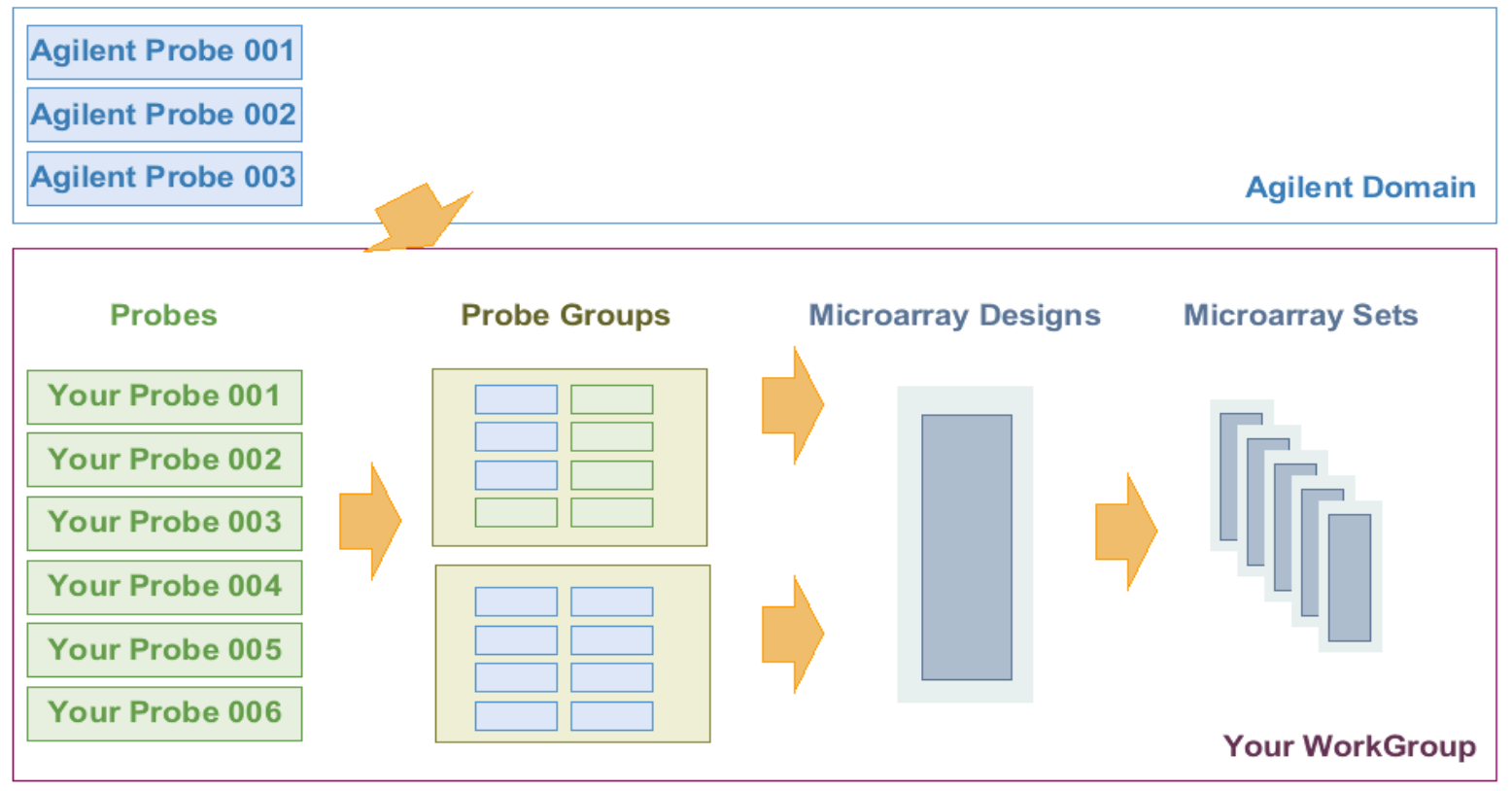

Figura 13 - Etapas para a criação de um array através da ferramenta eArray da empresa Agilent ${ }^{\mathrm{TM}}$. Fonte: https://earray.chem.agilent.com/earray/.

\section{3 - Melhoria da Anotação Funcional de P. vivax}

A última etapa realizada foi a adição de informações à anotação funcional existente do genoma de $P$. vivax. A ferramenta de anotação escolhida foi o GOPET (Vinayagam et al., 2006). Essa abordagem é baseada em classificação e foi selecionada por permitir realizar anotação funcional em larga escala, para diversos tipos de organismos, além de fornecer uma medida de credibilidade para cada predição. Para realizar a fase de classificação, é utilizada a metodologia SVM, que objetiva encontrar os parâmetros de um hiperplano ótimo que maximiza a margem de separação entre as classes. $O$ funcionamento do método GOPET é apresentado na Figura 14.

Anteriormente à anotação das sequências de interesse, o método passa por uma fase de treinamento utilizando sequências com funções conhecidas de 18 espécies, incluindo uma espécie do gênero Plasmodium ( $P$. falciparum), para estimar os hiperplanos ótimos de separação (OSHs) entre as anotações ditas verdadeiras (+1) ou falsas (-1). 
Training sequence

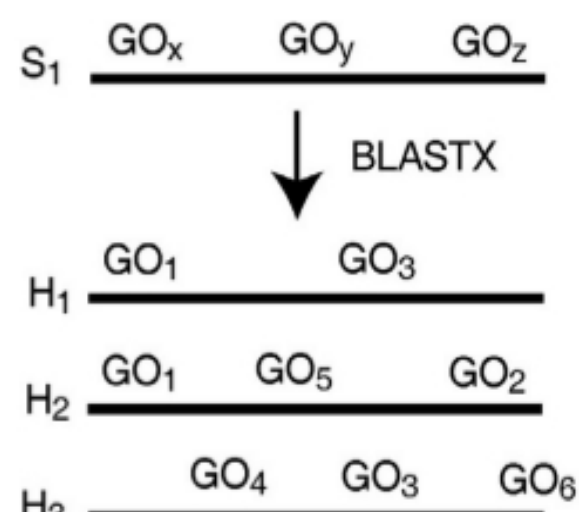

New sequence

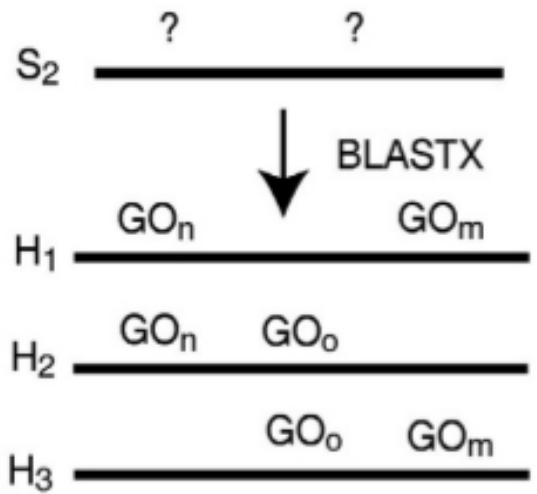

$\mathrm{H}_{3}$

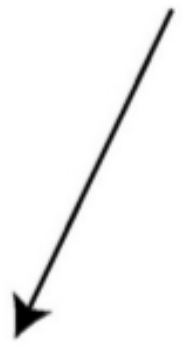

Attributes to $\mathrm{GO}$ terms
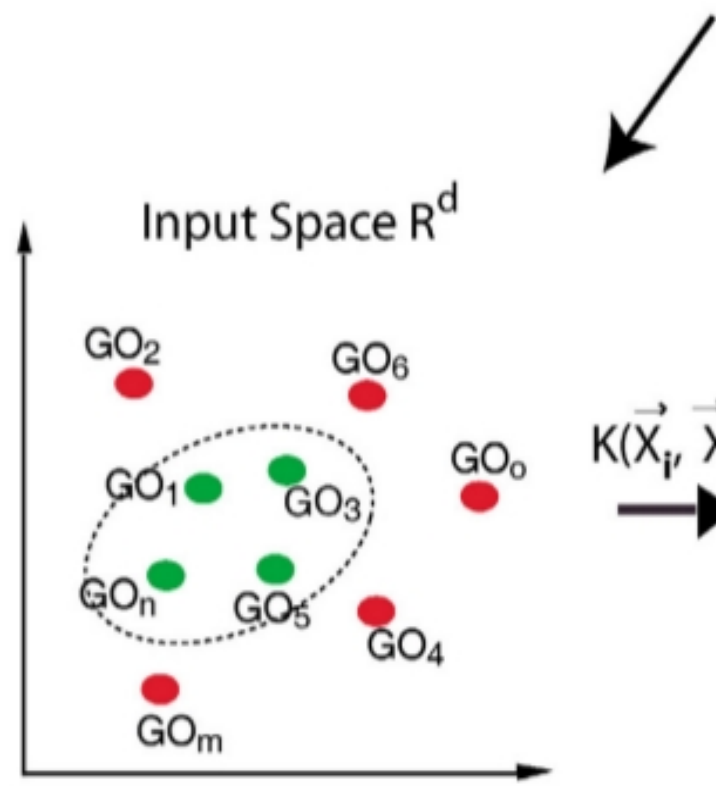

$=>$ For $\mathrm{S}_{2}: \mathrm{GO}_{\mathbf{n}}$

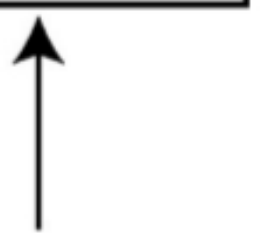

Feature Space H

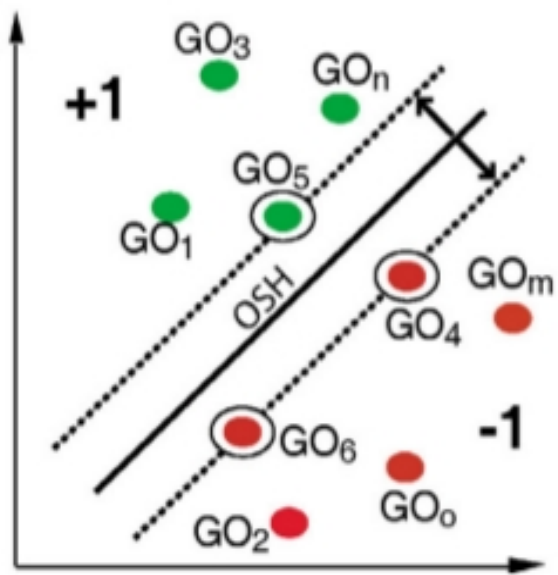

Figura 14 - Método de anotação por classificação utilizando SVM, implementado pela ferramenta GOPET. Fonte: Vinayagam et al., 2004. 
As sequências a serem anotadas são usadas como query em buscas em bancos de dados de proteínas e os termos de função molecular do Gene Ontology (GO) das proteínas mais similares são extraídos. Os atributos dos termos GO resultantes da busca das sequências alvo, como medidas de similaridade entre as sequências, frequência do termo, qualidade da anotação, nível hierárquico da anotação GO, entre outros, são então calculados e os termos são mapeados em um espaço de características. Posteriormente, utilizando os OSHs estimados na fase de treinamento, esses termos são classificados como "verdadeiros" ou "falsos", ou seja, verdadeiramente associados à determinada sequência ou não.

Ao todo, são utilizados 99 classificadores e é realizada uma abordagem de votação para definir se determinado termo GO é verdadeiramente associado a uma sequência de interesse específica, com um grau de credibilidade (ou probabilidade) dependente do número de classificadores em que o termo foi classificado como "verdadeiro".

Foram submetidas para anotação funcional utilizando a ferramenta GOPET todas as sequências de proteínas de $P$. vivax disponíveis na versão 8.0 do banco de dados PlasmoDB, totalizando 5435 sequências. 
4. Resultados 


\section{1 - Influência do baço na expressão gênica de $P$. vivax}

A partir de cada um dos modelos desenvolvidos, foram encontrados genes com um padrão de expressão que satisfazia a condição desejada: "ON" nos parasitas retirados de macacos com baço, $S p+2$, e "OFF" nos parasitas retirados de macacos sem baço, $S p-1$, Sp-2 e $S p-3$.

Conforme a primeira metodologia proposta, em que foram comparadas as regiões chamadas de foreground e background, onze genes obedeceram ao padrão determinado. Seu padrão de expressão é mostrado na Figura 15, em comparação com dois genes controle.

\section{Putative Spleen-Dependent Genes}

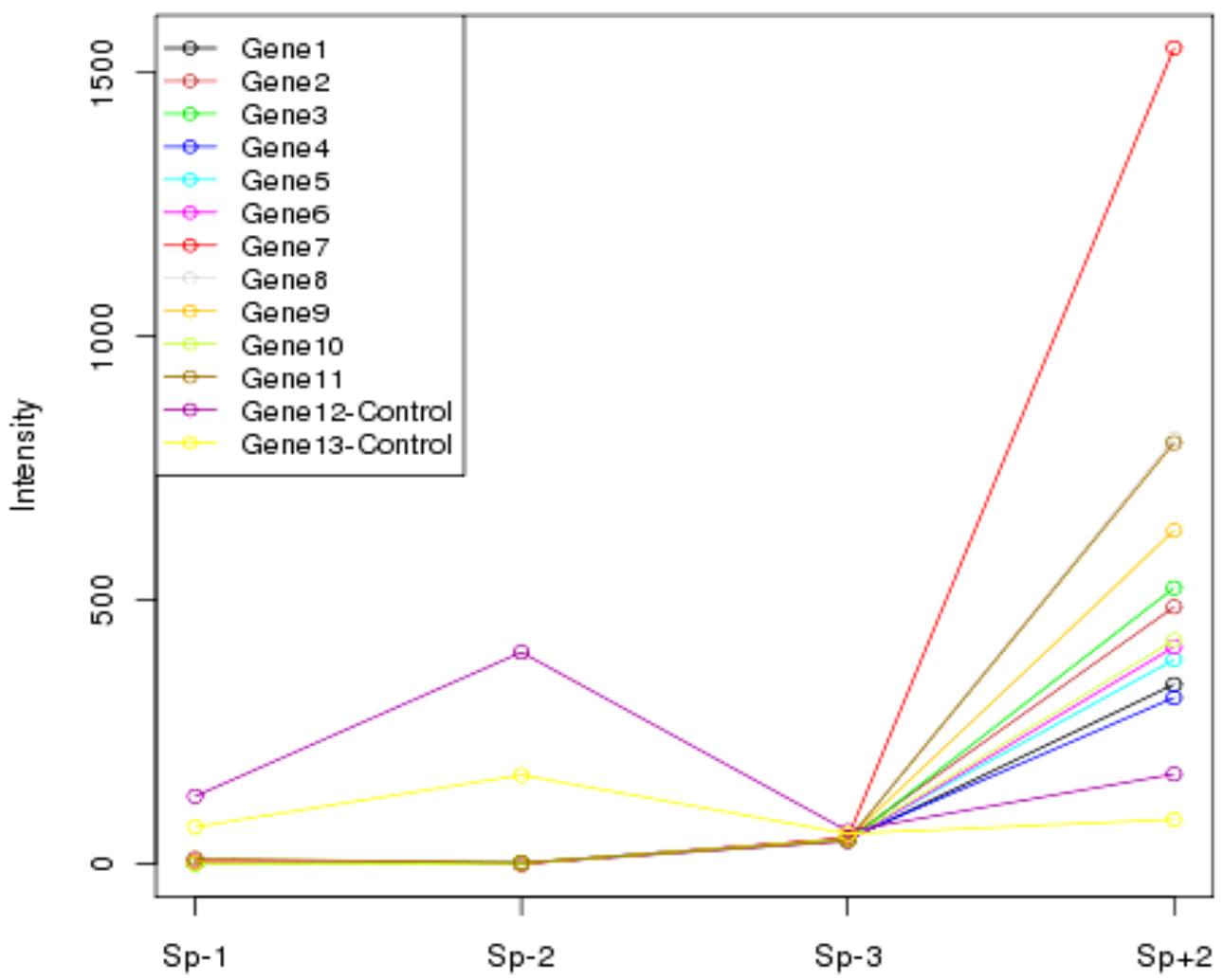

Figura 15 - Padrão de expressão dos genes resultantes da primeira análise, em que as regiões de foreground foram comparadas com seu background. 
Na segunda metodologia proposta, em que a intensidade média de expressão de cada spot foi comparada aos controles negativos da lâmina (Figura 16), 47 genes apresentaram o padrão "ON" nos parasitas extraídos de animais com baço e "OFF" nos parasitas extraídos de animais sem baço. Desses genes, quatro também tiveram o padrão definido pela primeira abordagem.

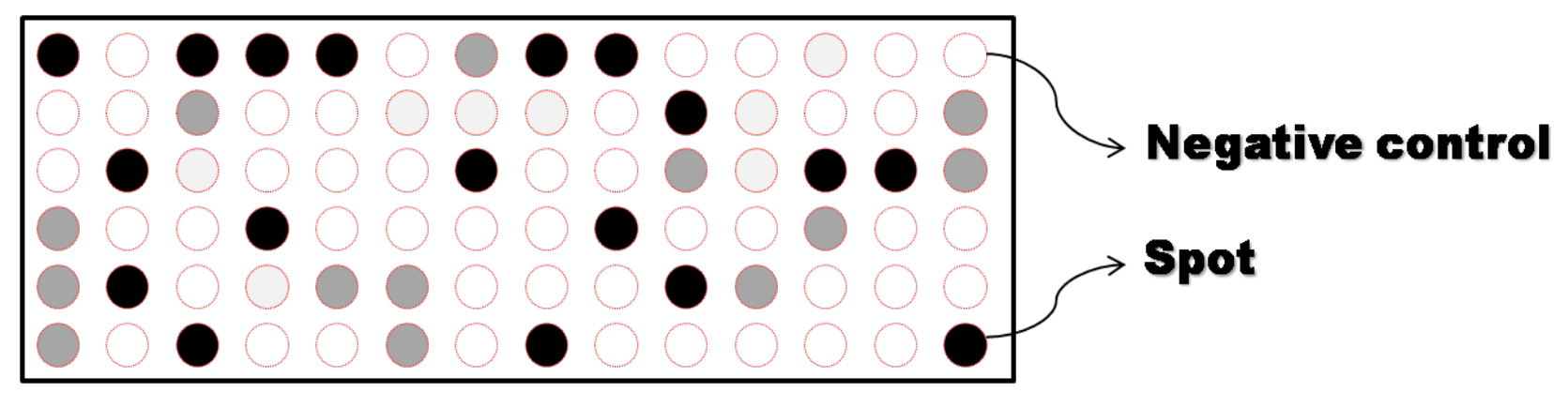

Figura 16 - Lâmina de microarray destacando as regiões utilizadas para a comparação no segundo modelo.

O terceiro método proposto, em que os genes de interesse apresentavam intensidade média menor que o quantil 0,98 dos controles negativos em Sp-1, Sp-2 e Sp3, e pelo menos dez vezes maior que o quantil 0,98 dos controles negativos em $5 p+2$, resultou em 40 genes com expressão seguindo o modelo.

A lista final, resultado da união das três metodologias (Figura 17), possui um total de 77 genes. Desses genes, 18 tiveram o padrão "ON" e "OFF" desejado em duas ou mais análises, enquanto dois genes, apresentaram esse padrão em todas as metodologias aplicadas.

Como cada uma das metodologias desenvolvidas teve uma abordagem diferente, considerando fatores distintos do microarray, obteve-se uma lista de genes diferente para cada análise, com alguns genes de interesse como resultado de mais de uma das análises. A lista contendo os genes candidatos a possuírem expressão dependente da presença do baço do hospedeiro foi enviada aos colaboradores do CRESIB para futura validação experimental. 


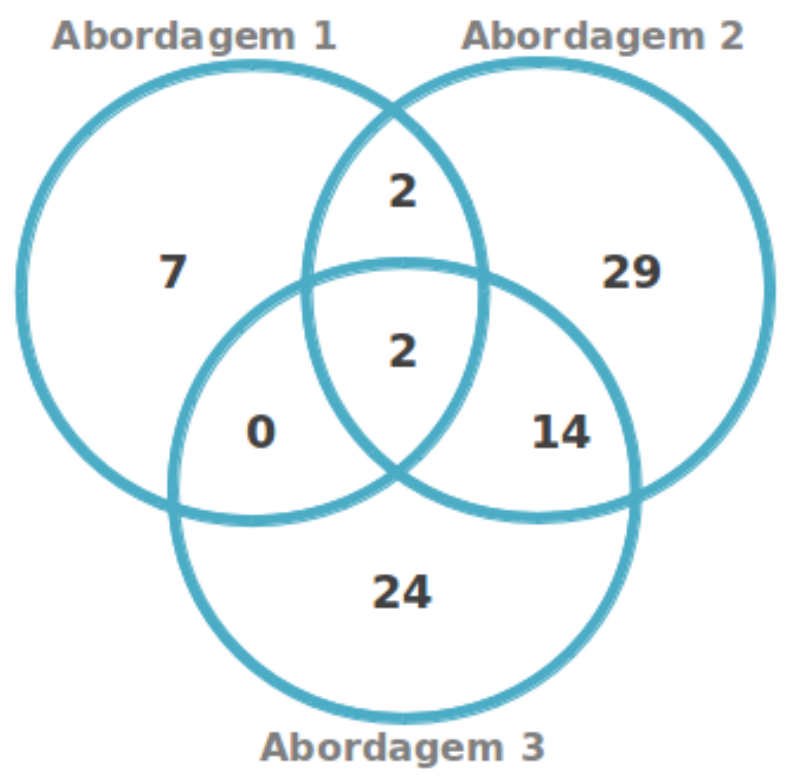

Figura 17 - Número de genes encontrados em cada uma das abordagens e sobreposição entre os métodos.

\section{2 - Desenho do tiling array}

As regiões dos éxons, juntamente com as regiões 5'UTR e 3'UTR do genoma de $P$. vivax foram utilizadas para o desenho das sondas do tiling array através do algoritmo chipD, descrito anteriormente. A lâmina projetada possui a configuração 1x1M, que apresenta um total de 974.016 spots disponíveis. No total, foram desenhadas 316.589 sondas, com tamanho de 60-mer cada uma, com uma extensa cobertura da região genômica de interesse. Cada sonda foi replicada três vezes na lâmina. Foram adicionadas também 6.001 sondas controle definidas pela empresa Agilent ${ }^{\mathrm{TM}}$.

Além disso, foi solicitado por nossos colaboradores que fossem acrescentadas ao chip três réplicas exatas do experimento de microarray realizado anteriormente para a análise da influência do baço na expressão gênica de $P$. vivax e também 107 sondas representando RNAs não-codificantes do parasita, identificados através de metodologias automáticas específicas para busca de RNAs não-codificantes (Machado-Lima et al., 2008). As sondas foram distribuídas aleatoriamente na lâmina de tiling array, para preventivamente evitar perda do sinal de um grupo inteiro de genes caso ocorram problemas técnicos espaciais na lâmina e para evitar outros tipos de vieses posicionais. 
Após a conclusão do design, o array foi enviado para fabricação pela empresa Agilent $^{\mathrm{TM}}$, sob responsabilidade do grupo do Dr. Hernando del Portillo. Os primeiros experimentos foram recentemente realizados por nossos colaboradores e a análise dos dados gerados deverá ser iniciada em breve.

\section{3 - Melhoria da Anotação Funcional de P. vivax}

No banco de dados PlasmoDB, estão disponíveis 5435 sequências de proteínas de P. vivax. Dessas, 3085 são caracterizadas como "hypotetical protein", o que fornece pouco significado biológico a respeito da função dessas moléculas, daí a necessidade de adicionar mais informações à anotação funcional desse parasita. A Figura 18 mostra uma representação dos principais termos encontrados na descrição dos produtos gênicos de $P$. vivax disponíveis no PlasmoDB.

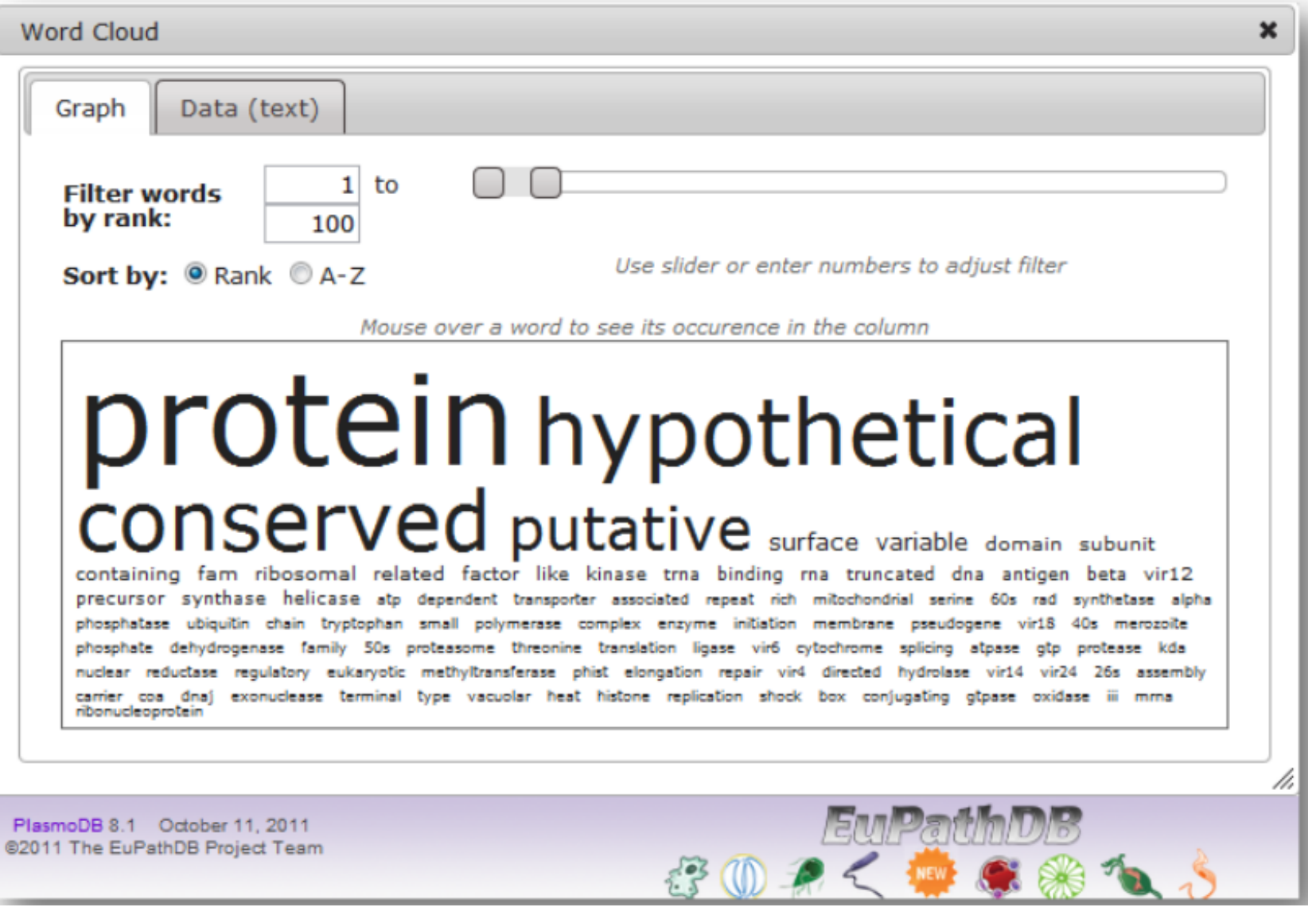

Figura 18 - Principais termos encontrados na descrição dos produtos gênicos de $P$. vivax. Fonte: plasmodb.org. 
Todas as sequências de proteínas de $P$. vivax disponíveis na versão 8.0 do banco de dados PlasmoDB foram utilizadas nessa etapa. No total, 5435 sequências foram submetidas para anotação funcional com termos GO utilizando a ferramenta GOPET.

Como resultado quantitativo, 2392 sequências, 44\% do total, obtiveram ao menos um termo GO funcional associado, utilizando um nível de credibilidade mínimo de 0,60 na ferramenta GOPET. Com o objetivo de associar termos às sequências não anotadas pela abordagem anterior, a credibilidade mínima foi reduzida para 0,50. Através dessa redução, mais 1104 sequências (20\% do total) também foram associadas a pelo menos um termo de anotação funcional do Gene Ontology.

Dessa forma, ao todo 3496 sequências (64\% do total) de $P$. vivax foram anotadas funcionalmente (Figura 19). Apesar da redução do valor de corte de confiabilidade possibilitar associar termos a sequências não anotadas anteriormente, pode elevar o número de falsos positivos, de modo que essas anotações devem ser utilizadas com mais cautela, sendo indicado se possível uma curagem manual.

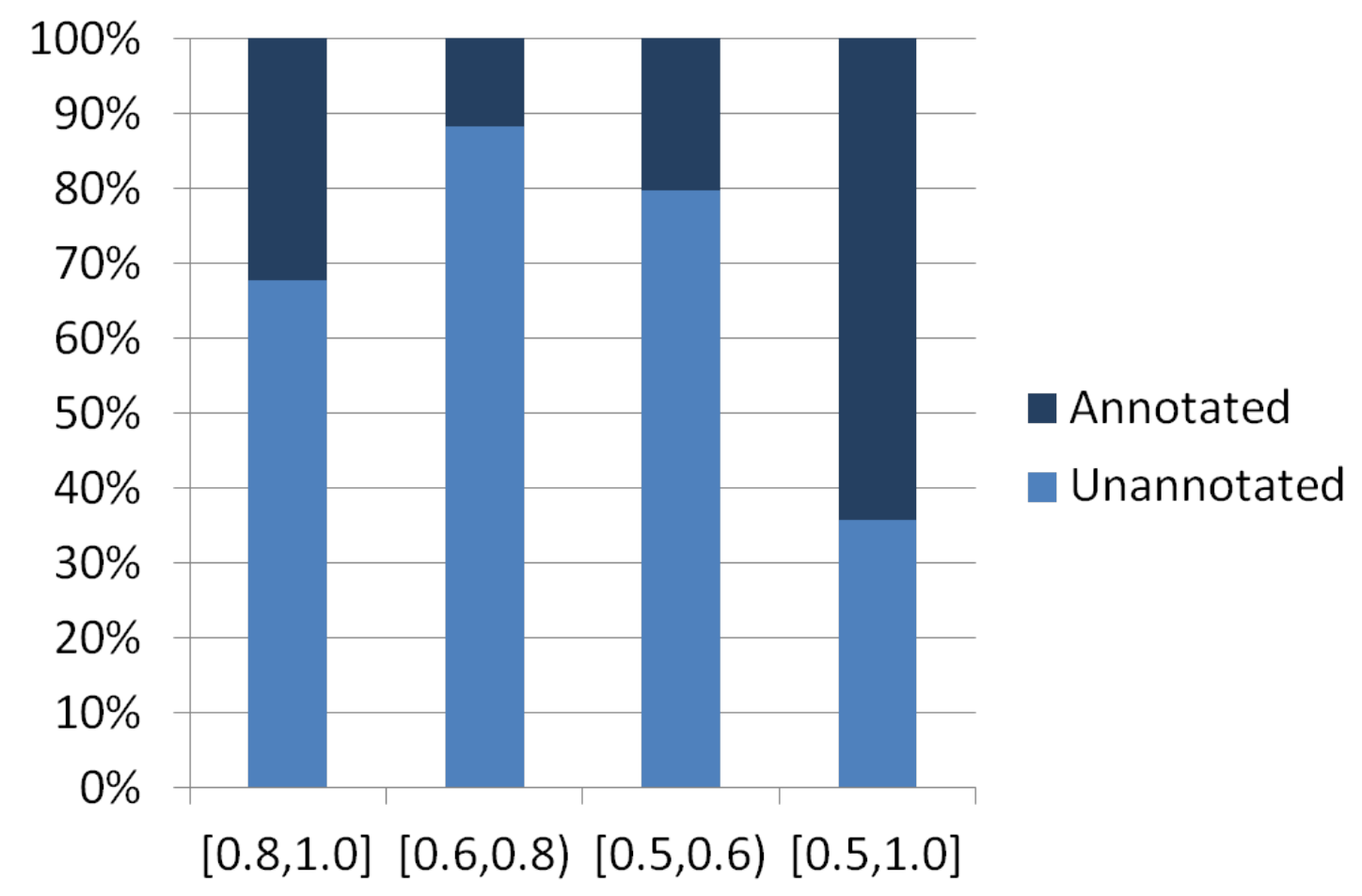

Figura 19 - Resultados quantitativos da anotação obtida através do método GOPET com diferentes níveis de confiabilidade. 
Segundo os autores da metodologia GOPET, as anotações que apresentam $80 \%$ ou mais de confiabilidade podem ser prontamente utilizadas. No caso de $P$. vivax, 1751 sequências foram anotadas com esse nível de confiança, o que representa mais de 30\% das anotações obtidas.

Os principais termos GO associados às sequências de $P$. vivax são apresentados na Figura 20 e o nível dos termos na ontologia GO, na Figura 21, ambas construídas com a ferramenta Blast2GO (Conesa et al., 2005; Aparicio et al., 2006).

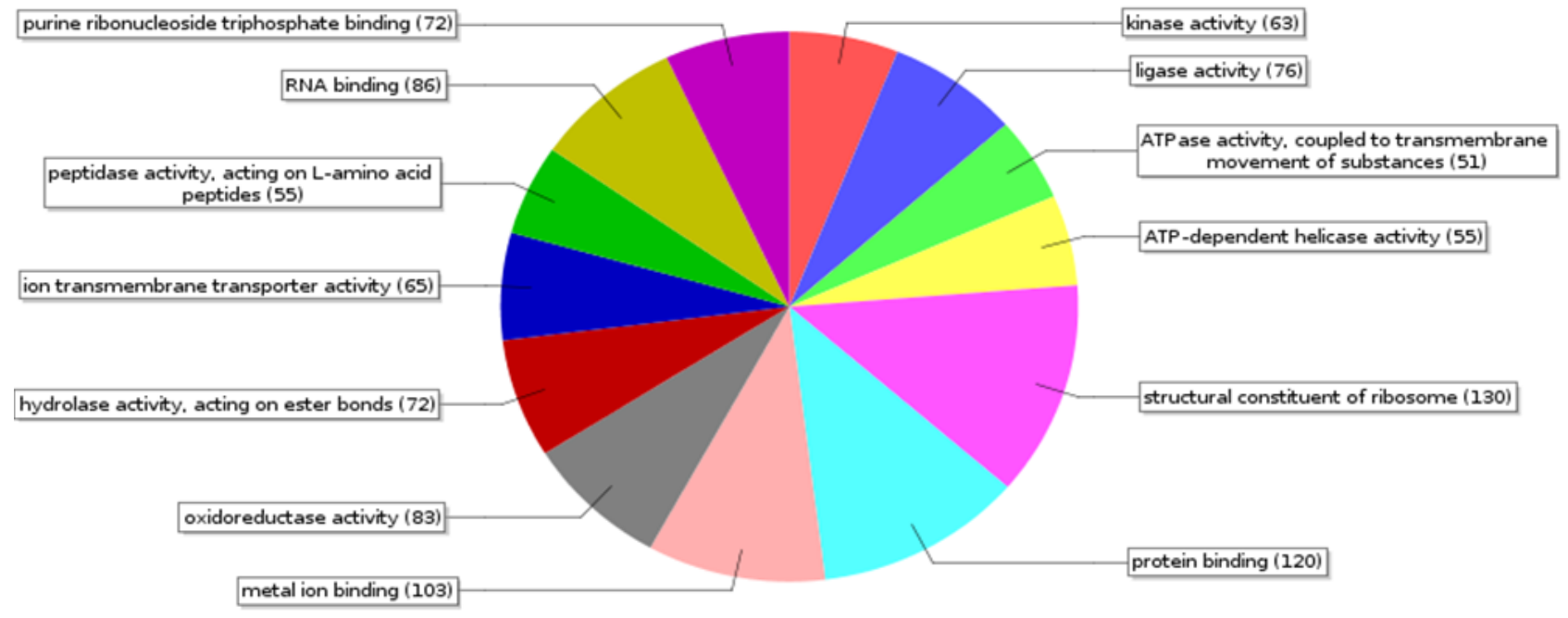

Figura 20 - Principais termos GO associados às proteínas de $P$. vivax.

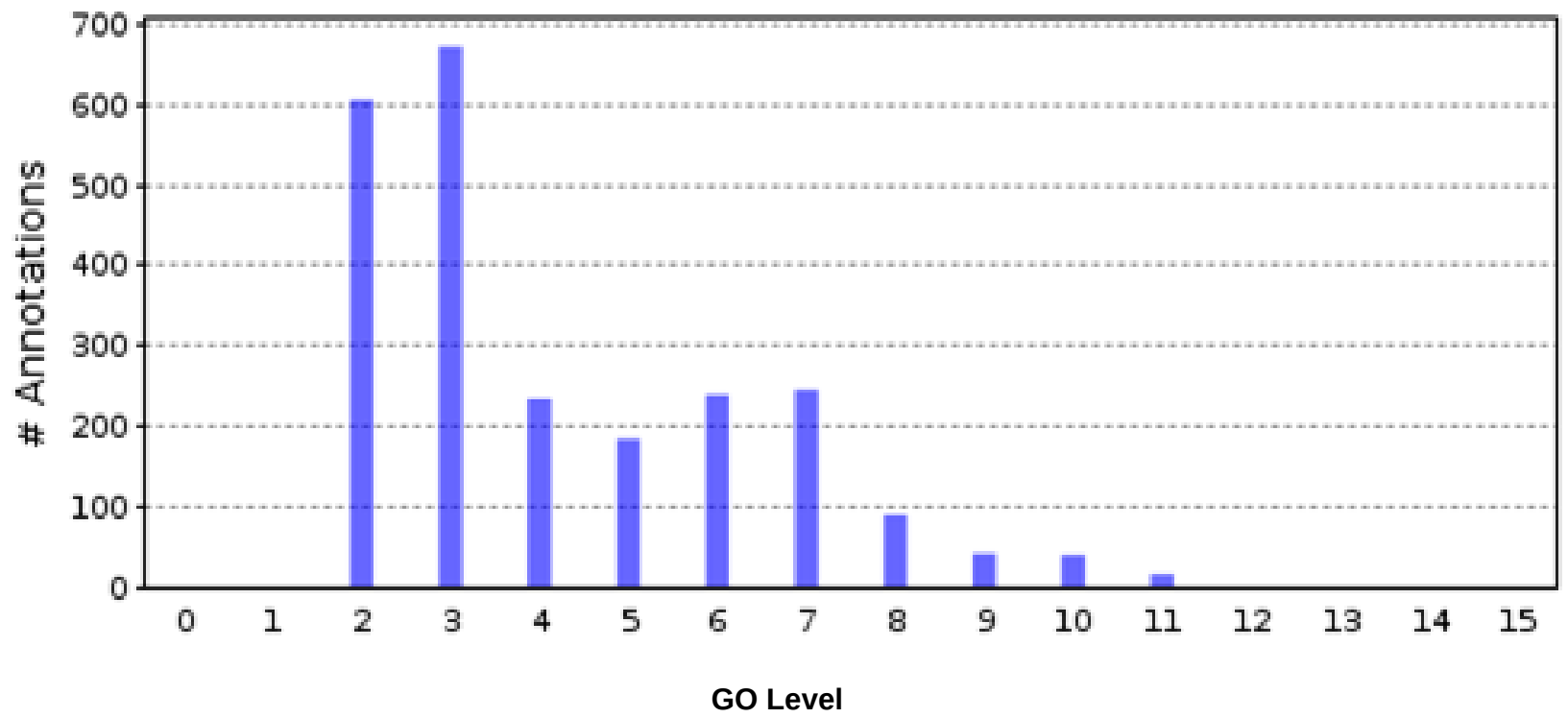

Figura 21 - Número de anotações obtidas em cada nível da ontologia GO. 
A grande maioria das anotações obtidas estão nos níveis dois e três da ontologia de função molecular do GO. Apesar dos diferentes ramos do GO possuírem profundidades distintas, em geral os termos encontrados nos níveis basais são considerados mais genéricos, com menor conteúdo informacional. Entretanto, de forma geral, esses foram os termos que apresentaram maior confiabilidade na anotação.

De todas as proteínas as quais foram associados termos GO, 732 que anteriormente estavam descritas como "hypotetical protein" obtiveram anotação funcional. Entre os genes resultantes das análises de expressão dependente do baço descritos apenas como geradores de "proteínas hipotéticas", três foram associados a termos funcionais.

A anotação resultante desse trabalho está disponível no seguinte endereço: http://labpib.fmrp.usp.br/-bcorrea/annotation-pvivax-GOPET/. 
5. Discussão e Considerações Finais 
A biologia de Plasmodium vivax ainda possui muitos aspectos a serem desvendados. Compreender o papel do baço do hospedeiro na expressão gênica de $P$. vivax é um ponto importante não apenas para o combate à doença mas também para a elucidação dos mecanismos complexos presentes na relação entre parasita e hospedeiro, evolutivamente desenvolvidos e selecionados ao longo de milhares de anos.

Experimentos utilizando microarray foram realizados anteriormente com sucesso para a investigação de diversas questões relacionadas a $P$. vivax assim como a outras espécies do gênero Plasmodium (Ntumngia et al., 2005; Bozdech et al., 2008; Cunningham et al., 2009; Su et al., 2009; Dharia et al., 2010; Tan et al., 2011). No caso da primeira etapa do presente estudo, a técnica foi aplicada para verificar a influência do baço do hospedeiro na expressão gênica de $P$. vivax.

Diferente da busca por genes diferencialmente expressos, a identificação de genes "ON" e "OFF" fornece uma medida mais extrema de expressão, buscando mudanças mais drásticas nos níveis de expressão gênica do parasita, que fornece como resultado genes com diferenças mais acentuadas nos níveis de expressão, sem necessariamente descartar uma análise posterior de expressão diferencial, frequentemente realizada em experimentos de microarray.

Os modelos estatísticos desenvolvidos no presente trabalho mostraram-se capazes de realizar a identificação de genes expressos e não-expressos. Os valores de corte definidos em cada um dos modelos foram escolhidos visando realizar uma análise bastante estringente, para que fosse possível chegar a uma lista final com um número de genes factível de validação experimental, segundo solicitação dos colaboradores do estudo.

Conforme o esperado, obteve-se listas de genes diferentes para cada uma das análises, pois cada uma das metodologias propostas abordou aspectos distintos do microarray, como o sinal de background e os controles negativos presentes nas lâminas. Ainda assim, alguns genes de interesse apareceram como resultado de mais de um dos modelos.

A segunda fase do trabalho consistiu em projetar um tiling array de $P$. vivax, com o objetivo de replicar o microarray realizado anteriormente, além de adicionar novas informações para a compreensão do mecanismo utilizado pelo parasita para o escape do baço do hospedeiro.

Os tiling arrays, combinados com métodos computacionais de análise, podem fornecer informações valiosas para a compreensão global de processos presentes nos 
sistemas biológicos. Concorrentemente, as tecnologias atuais de sequenciamento de transcritoma, conhecidas por RNA-Seq, vem sendo cada vez mais utilizadas, devido à sua maior precisão em comparação com as metodologias baseadas em hibridização e à crescente redução do custo por experimento. Apesar disso, métodos como os tiling arrays, permanecem bastante úteis para mensurar os níveis de expressão gênica (Malone et al., 2011).

Estudos comparativos entre tiling arrays e RNA-Seq mostram que os tiling arrays são capazes de detectar níveis de expressão gênica com baixo custo de forma efetiva, enquanto que a metodologia de RNA-Seq é capaz de garantir uma maior acurácia em diversos casos, de modo que é necessário realizar a escolha adequada da metodologia levando em conta os objetivos específicos do estudo ou, se possível, a união das duas técnicas de forma complementar (Agarwal et al., 2010).

No caso do presente trabalho, a escolha pelo tiling array foi devida à sua capacidade de mensurar expressão gênica em larga escala com um menor custo, já que o grupo de pesquisa colaborador já havia realizado estudos prévios com metodologias baseadas em hibridização, possuindo os equipamentos necessários e conhecimento a respeito desse tipo de técnica, utilizados para os futuros experimentos com o tiling array projetado.

Nesse paradigma tecnológico de experimentação em transcritoma, o foco foi deslocado da manufatura das ferramentas experimentais para o seu planejamento. 0 projeto de tais chips passou a ser a etapa mais importante, uma vez que existem empresas especializadas na confecção das lâminas de tiling array, o que facilita sua produção experimental. Algumas dessas empresas, com uma visão similar à do software livre, de plataforma aberta, permitem que o usuário tenha pleno controle sobre as sondas a serem desenhadas. A escolha e design de tais sondas, principalmente para organismos não-modelo, ficam sob responsabilidade do pesquisador, fazendo com que essa seja uma etapa crucial para a realização de um experimento de tiling array.

A empresa Agilent ${ }^{\mathrm{TM}}$ (http://www.home.agilent.com/), uma das mais conceituadas na área e que permite um desenho personalizado da lâmina de tiling array, foi contratada para a confecção do array.

Para o desenho das sondas, são necessários intensivos esforços através de ferramentas de bioinformática para determinar e localizar as sequências de interesse, além de processá-las do modo necessário para a produção do chip. Diversos algoritmos estão disponíveis para a realização dessa tarefa, de modo que a escolha e o 
planejamento correto é fundamental para garantir a qualidade do tiling array e, dessa forma, possibilitar sua utilização para a realização de experimentos e a interpretação biológica correta dos resultados obtidos.

A lâmina desenhada servirá não somente para mais investigações relacionadas ao papel do baço na expressão gênica de $P$. vivax como também para outros tipos de questões, como o estudo de RNAs não-codificantes e das regiões 5'UTR e 3'UTR do genoma do parasita, a serem realizados em breve pelos colaboradores do presente trabalho.

A terceira e última etapa do projeto esteve relacionada à adição de informação à anotação funcional existente dos produtos gênicos de $P$. vivax, com o objetivo de auxiliar na interpretação dos resultados obtidos nos experimentos de microarray e tiling array já realizados e também em estudos futuros.

Anotação funcional de genes é uma etapa crucial para estudos em biologia molecular. Além disso, a reanotação é considerada por alguns autores como um passo inicial quase que obrigatório para estudos de genômica funcional, podendo melhorar a quantidade e qualidade das anotações disponíveis e assim levar a diferentes interpretações biológicas dos resultados obtidos (Berg et al., 2010).

As primeiras iniciativas para anotação funcional eram baseadas em linguagem natural, sem qualquer tipo de padronização, o que dificultava sua interpretação e comparação com outras fontes de anotação (Plessis et al., 2011). Ontologias biológicas são atualmente muito utilizadas para anotação funcional por serem estruturadas e padronizadas, o que facilita a aplicação por metologias automáticas (Bodenreider et al., 2006).

Uma das mais utilizadas é o Gene Ontology, que fornece um vocabulário unificado, controlado, padronizado e estruturado de termos para descrever os produtos gênicos. Considerando que genes similares de diferentes espécies podem ter funções conservadas, o GO pode ser utilizado independentemente do organismo de estudo, possibilitando que sejam realizadas comparações e integrações entre diversas bases de dados de anotações (Defoin-Platel et al., 2011).

Apesar de suas muitas vantagens, o GO também possui diversas limitações, como por exemplo a maioria das suas anotações, cerca de 98\%, é de origem automática (Defoin-Platel et al., 2011); ainda há poucos termos relacionados a funções e estruturas específicas de protistas, como $P$. vivax; os termos não estão ligados diretamente a vias metabólicas; entre outros, sendo necessário, se possível, complementar a anotação com 
informações provenientes de outros bancos de dados. Como exemplo de mais informações a serem agregadas, pode-se considerar OrthoMCL (Li et al., 2003; Chen et al., 2006) e EggNOG (Jensen et al., 2008; Muller et al., 2010; Powel et al., 2012), capazes de fornecer informações que consideram relações de ortologia; KEGG Orthology e Enzyme Commission numbers (EC numbers), capazes também de associar termos com ligação aos padrões metabólicos disponíveis no KEGG (Mao et al., 2005); entre outros bancos de dados.

Metodologias estatísticas tentam minimizar as limitações encontradas no Gene Ontology e a propagação de erros de anotação, além quantificar a confiabilidade das anotações resultantes. Existem diversos métodos para associar termos GO a sequências, como por exemplo os que utilizam técnicas de aprendizado de máquinas. Esse tipo de abordagem, apesar de ainda não ser a mais amplamente utilizada para fins de anotação, apresenta um melhor desempenho em termos de acurácia de predição em muitos casos, por considerar dados de treinamento positivos e negativos (Leslie et al., 2004; Saraç et al., 2010).

No caso de $P$. vivax, a anotação disponível no banco de dados PlasmoDB ainda possui relativamente pouca informação funcional. Das 5435 proteínas do parasita disponíveis, mais da metade estão anotadas como "hypothetical protein". Esse tipo anotação traz pouca informação sobre a real função dessas moléculas. Além disso, apenas uma minoria delas apresentam termos GO associados, mesmo que apenas potencialmente associados. Dessa forma, agregar informação funcional a essas sequências é um passo importante e que demanda mais esforços.

O método GOPET utilizado nesse trabalho é baseado na abordagem de SVM e foi escolhido por permitir realizar anotação funcional em larga escala, independentemente do organismo de estudo, e por fornecer uma medida de credibilidade para cada predição (Vinayagam et al., 2006).

Sabe-se que a aplicação de apenas uma metodologia não será capaz de solucionar completamente a falta de informação a respeito da anotação de $P$. vivax. Os resultados encontrados no presente trabalho representam uma importante contribuição nesse aspecto, mas que idealmente devem ser combinados com outras outras abordagens, utilizando diferentes bancos de dados e, na medida do possível, validados experimentalmente. Apesar disso, espera-se que as informações adicionadas à anotação de $P$. vivax resultantes desse trabalho possam auxilar na interpretação biológica dos resultados encontrados nos estudos de microarray e tiling array realizados. 
Dessa forma, ao realizar um estudo relacionado aos mecanismos utilizados por $P$. vivax para escapar da eliminação do baço do hospedeiro, através de abordagens computacionais, esperou-se contribuir para a compreensão de um dos aspectos fundamentais da biologia de um dos principais parasitas causadores da malária humana. 
7. REFERÊNCIAS 
AGARWAL, A.; KOPPSTEIN, D.; ROZOWSKY, J. et al. Comparison and calibration of transcriptome data from RNA-Seq and tiling arrays. BMC genomics, v. 11, n. 1, p. 383, jun 2010.

ANSTEY, N. M.; RUSSELL, B.; YEO, T. W.; PRICE, R. N. The pathophysiology of vivax malaria. Trends in parasitology, v. 25, n. 5, p. 220-7, maio 2009.

APARICIO, G.; GÖTZ, S.; CONESA, A. et al. Blast2GO goes grid: developing a gridenabled prototype for functional genomics analysis. Studies in health technology and informatics, v. 120, p. 194-204, jan 2006.

AURRECOECHEA, C.; BRESTELLI, J.; BRUNK, B. P. et al. PlasmoDB: a functional genomic database for malaria parasites. Nucleic acids research, v. 37, n. Database issue, p. D539-43, jan 2009.

BACHMANN, A.; ESSER, C.; PETTER, M. et al. Absence of erythrocyte sequestration and lack of multicopy gene family expression in Plasmodium falciparum from a splenectomized malaria patient. Plos one, v. 4, n. 10, p. e7459, jan 2009.

BARCUS, M. J.; BASRI, H.; PICARIMA, H. et al. Demographic Risk Factors for Severe and Fatal Vivax and Falciparum Malaria Among Hospital Admissions in Northeastern Indonesian Papua. Am J Trop Med Hyg, v. 77, n. 5, p. 984-991, nov 2007.

BASSAT, Q.; ALONSO, P. L. Defying malaria: Fathoming severe Plasmodium vivax disease. Nature medicine, v. 17, n. 1, p. 48-9, jan 2011.

BERG, B. H. J. VAN DEN; MCCARTHY, F. M.; LAMONT, S. J.; BURGESS, S. C. Reannotation is an essential step in systems biology modeling of functional genomics data. Plos one, v. 5, n. 5, p. e10642, jan 2010.

BERNABEU, M.; LOPEZ, F.; FERRER, M. et al. Functional analysis of Plasmodium vivax VIR proteins reveals different subcellular localizations and cytoadherence to the ICAM-1 endothelial receptor. Cellular microbiology, 21 nov 2011.

BODENREIDER, O.; STEVENS, R. Bio-ontologies: current trends and future directions. Briefings in bioinformatics, v. 7, n. 3, p. 256-74, set 2006. 
BOZDECH, Z.; MOK, S.; HU, G. et al. The transcriptome of Plasmodium vivax reveals divergence and diversity of transcriptional regulation in malaria parasites. Proceedings of the National Academy of Sciences of the United States of America, v. 105, n. 42, p. 16290-5, out 2008.

BULYK, M. L. DNA microarray technologies for measuring protein-DNA interactions. Current opinion in biotechnology, v. 17, n. 4, p. 422-30, ago 2006.

CARLTON, J. M.; ADAMS, J. H.; SILVA, J. C. et al. Comparative genomics of the neglected human malaria parasite Plasmodium vivax. Nature, v. 455, n. 7214, p. 75763, 2008.

CARLTON, J. M.; SINA, B. J.; ADAMS, J. H. Why Is Plasmodium vivax a Neglected Tropical Disease? PLoS neglected tropical diseases, v. 5, n. 6, p. e1160, jun 2011.

CARVALHO, B. O.; LOPES, S. C. P.; NOGUEIRA, P. A; et al. On the Cytoadhesion of Plasmodium vivax-Infected Erythrocytes. The Journal of infectious diseases, $v$. 202, jun 2010.

CHEN, F.; MACKEY, A. J.; STOECKERT, C. J.; ROOS, D. S. OrthoMCL-DB: querying a comprehensive multi-species collection of ortholog groups. Nucleic acids research, v. 34, n. Database issue, p. D363-8, 1 jan 2006.

CHOU, H.-H.; HSIA, A.-P.; MOONEY, D. L.; SCHNABLE, P. S. Picky: oligo microarray design for large genomes. Bioinformatics (Oxford, England), v. 20, n. 17, p. 2893902, nov 2004.

CONESA, A.; GÖTZ, S.; GARCÍA-GÓMEZ, J. M. et al. Blast2GO: a universal tool for annotation, visualization and analysis in functional genomics research. Bioinformatics (Oxford, England), v. 21, n. 18, p. 3674-6, set 2005.

CUNNINGHAM, D.; FONAGER, J.; JARRA, W. et al. Rapid changes in transcription profiles of the Plasmodium yoelii yir multigene family in clonal populations: lack of epigenetic memory? PloS one, v. 4, n. 1, p. e4285, jan 2009.

DAS, A.; SHARMA, M.; GUPTA, B.; DASH, A. P. Plasmodium falciparum and Plasmodium vivax: so similar, yet very different. Parasitology research, v. 105, n. 4, p. 1169-71, out 2009. 
DEFOIN-PLATEL, M.; HINDLE, M. M.; LYSENKO, A. et al. AIGO: Towards a unified framework for the Analysis and the Inter-comparison of GO functional annotations. BMC Bioinformatics, v. 12, n. 1, p. 431, 2011.

DHARIA, N. V.; BRIGHT, A. T.; WESTENBERGER, S. J. et al. Whole-genome sequencing and microarray analysis of ex vivo Plasmodium vivax reveal selective pressure on putative drug resistance genes. Proceedings of the National Academy of Sciences of the United States of America, v. 107, n. 46, p. 20045-50, out 2010.

DUFOUR, Y. S.; WESENBERG, G. E.; TRITT, A. J. et al. chipD: a web tool to design oligonucleotide probes for high-density tiling arrays. Nucleic acids research, v. 38 Suppl, p. W321-5, jul 2010.

ENGELHARDT, B. E.; JORDAN, M. I.; BRENNER, S. E. A graphical model for predicting protein molecular function. Proceedings of the 23rd international conference on Machine learning - ICML '06, p. 297-304, 2006.

ENGELHARDT, B. E.; JORDAN, M. I.; MURATORE, K. E.; BRENNER, S. E. Protein molecular function prediction by Bayesian phylogenomics. PLoS computational biology, v. 1, n. 5, p. e45, out 2005.

ENGELHARDT, B. E.; JORDAN, M. I.; REPO, S. T.; BRENNER, S. E. Phylogenetic molecular function annotation. Journal of physics, v. 180, n. 1, p. 12024, jan 2009.

ENGWERDA, C. R.; BEATTIE, L.; AMANTE, F. H. The importance of the spleen in malaria. Trends in parasitology, v. 21, n. 2, p. 75-80, fev 2005.

FERNANDEZ-BECERRA, C.; YAMAMOTO, M. M.; VÊNCIO, R. Z. N. et al. Plasmodium vivax and the importance of the subtelomeric multigene vir superfamily. Trends in parasitology, v. 25, n. 1, p. 44-51, jan 2009.

GENTON, B.; D'ACREMONT, V.; RARE, L. et al. Plasmodium vivax and mixed infections are associated with severe malaria in children: a prospective cohort study from Papua New Guinea. PLoS medicine, v. 5, n. 6, p. e127, jun 2008.

GRÄF, S.; NIELSEN, F. G. G.; KURTZ, S. et al. Optimized design and assessment of whole genome tiling arrays. Bioinformatics (Oxford, England), v. 23, n. 13, p. i195204, 1 jul 2007. 
GUERRA, C. A.; HOWES, R. E.; PATIL, A. P. et al. The International Limits and Population at Risk of Plasmodium vivax Transmission in 2009. PLoS Neglected Tropical Diseases, v. 4, n. 8, p. e774, ago 2010.

HERRERA, S.; PERLAZA, B. L.; BONELO, A.; ARÉVALO-HERRERA, M. Aotus monkeys: their great value for anti-malaria vaccines and drug testing. International journal for parasitology, v. 32, n. 13, p. 1625-35, 4 dez 2002.

Homepage eArray - Agilent $^{\mathrm{TM}}$ - https://earray.chem.agilent.com/earray. [Último acesso em outubro de 2011].

Homepage Empresa Agilent ${ }^{\mathrm{TM}}$ - http://www.home.agilent.com/agilent. [Último acesso em outubro de 2011].

Homepage GenBank - http://ncbi.nlm.nih.gov/genbank. [Último acesso em janeiro de 2012].

Homepage Gene Ontology - http://www.geneontology.org/. [Último acesso em outubro de 2011].

Homepage National Human Genome Research Institute - http://genome.gov. [Último acesso em janeiro de 2012].

Homepage Ministério da saúde do Brasil - http://portal.saude.gov.br. [Último acesso em outubro de 2011].

Homepage PlasmoDB - http://plasmodb.org. [Último acesso em janeiro de 2012].

Homepage R - http://www.r-project.org/. [Último acesso em dezembro de 2011].

JENSEN, L. J.; JULIEN, P.; KUHN, M. et al. eggNOG: automated construction and annotation of orthologous groups of genes. Nucleic acids research, v. $36, \mathrm{n}$. Database issue, p. D250-4, jan 2008.

JI, H.; WONG, W. H. TileMap: create chromosomal map of tiling array hybridizations. Bioinformatics (Oxford, England), v. 21, n. 18, p. 3629-36, 15 set 2005.

JIANG, C.; PUGH, B. F. Nucleosome positioning and gene regulation: advances through genomics. Nature reviews. Genetics, v. 10, n. 3, p. 161-72, mar 2009. 
JOURDREN, L.; DUCLOS, A.; BRION, C. et al. Teolenn: an efficient and customizable workflow to design high-quality probes for microarray experiments. Nucleic acids research, v. 38, n. 10, p. e117, jun 2010.

KITCHEN, S. F. The Infection of Reticulocytes by Plasmodium Vivax. Am J Trop Med Hyg. S1-18(4):347-359, 1938.

KOCHAR, D. K.; DAS, A.; KOCHAR, S. K. et al. Severe Plasmodium vivax Malaria: A Report on Serial Cases from Bikaner in Northwestern India. Am J Trop Med Hyg, v. 80, n. 2, p. 194-198, 2009.

KOONIN, E. V. Bridging the gap between sequence and function. Trends in genetics : TIG, v. 16, n. 1, p. 16, jan 2000.

LEI, H.; FUKUSHIGE, T.; NIU, W. et al. A widespread distribution of genomic CeMyoD binding sites revealed and cross validated by ChIP-Chip and ChIP-Seq techniques. Plos one, v. 5, n. 12, p. e15898, jan 2010.

LESLIE, C. S.; ESKIN, E.; COHEN, A.; WESTON, J.; NOBLE, W. S. Mismatch string kernels for discriminative protein classification. Bioinformatics (Oxford, England), v. 20, n. 4, p. 467-76, 1 mar 2004.

LI, L.; STOECKERT, C. J.; ROOS, D. S. OrthoMCL: identification of ortholog groups for eukaryotic genomes. Genome research, v. 13, n. 9, p. 2178-89, set 2003.

LI, X.; HE, Z.; ZHOU, J. Selection of optimal oligonucleotide probes for microarrays using multiple criteria, global alignment and parameter estimation. Nucleic acids research, v. 33 , n. 19, p. 6114-23, jan 2005.

LINDEMAN, L. C.; REINER, A. H.; MATHAVAN, S.; ALESTRÖM, P.; COLLAS, P. Tiling Histone H3 Lysine 4 and 27 Methylation in Zebrafish Using High-Density Microarrays. PLoS ONE, v. 5, n. 12, p. e15651, dez 2010.

LIU, X. S. Getting started in tiling microarray analysis. PLoS computational biology, v. 3, n. 10, p. 1842-4, out 2007.

MACHADO-LIMA, A.; PORTILLO, H. A DEL; DURHAM, A. M. Computational methods in noncoding RNA research. Journal of mathematical biology, v. 56, n. 1-2, p. 15-49, 
jan 2008.

MALONE, J. H.; OLIVER, B. Microarrays, deep sequencing and the true measure of the transcriptome. BMC biology, v. 9, p. 34, jan 2011.

MAO, X.; CAI, T.; OLYARCHUK, J. G.; WEI, L. Automated genome annotation and pathway identification using the KEGG Orthology (KO) as a controlled vocabulary. Bioinformatics (Oxford, England), v. 21, n. 19, p. 3787-93, 1 out 2005.

MARTIN-JAULAR, L.; FERRER, M.; CALVO, M. et al. Strain-specific spleen remodelling in Plasmodium yoelii infections in Balb/c mice facilitates adherence and spleen macrophage-clearance escape. Cellular microbiology, v. 13, n. 1, p. 109-22, jan 2011.

MEBIUS, R. E.; KRAAL, G. Structure and function of the spleen. Nature reviews. Immunology, v. 5, n. 8, p. 606-16, ago 2005.

MOCKLER, T. C.; CHAN, S.; SUNDARESAN, A. et al. Applications of DNA tiling arrays for whole-genome analysis. Genomics, v. 85, n. 1, p. 1-15, jan 2005.

MUELLER, I.; GALINSKI, M. R.; BAIRD, J. K. et al. Key gaps in the knowledge of Plasmodium vivax, a neglected human malaria parasite. The Lancet infectious diseases, v. 9, n. 9, p. 555-66, set 2009.

MULLER, J.; SZKLARCZYK, D.; JULIEN, P. et al. eggNOG v2.0: extending the evolutionary genealogy of genes with enhanced non-supervised orthologous groups, species and functional annotations. Nucleic acids research, v. 38, n. Database issue, p. D190-5, jan 2010.

NTUMNGIA, F. B.; BAHAMONTES-ROSA, N.; KUN, J. F. J. Genes coding for tryptophanrich proteins are transcribed throughout the asexual cycle of Plasmodium falciparum. Parasitology research, v. 96, n. 6, p. 347-53, ago 2005.

PARAKH, A.; AGARWAL, N.; AGGARWAL, A.; ANEJA, A. Plasmodium vivax malaria in children: uncommon manifestations. Annals of tropical paediatrics, v. 29, n. 4, p. 253-6, dez 2009. 
PEREIRA, E. A; ISHIKAWA, E. A.; FONTES, C. J. Adherence to Plasmodium vivax malaria treatment in the Brazilian Amazon Region. Malaria journal, v. 10, n. 1, p. 355, 13 dez 2011.

PLESSIS, L. DU; SKUNCA, N.; DESSIMOZ, C. The what, where, how and why of gene ontology--a primer for bioinformaticians. Briefings in bioinformatics, 17 fev 2011.

PORTILLO, H. A DEL; FERNANDEZ-BECERRA, C.; BOWMAN, S. et al. A superfamily of variant genes encoded in the subtelomeric region of Plasmodium vivax. Nature, $v$. 410, n. 6830, p. 839-42, abr 2001.

PORTILLO, H. A DEL; FERRER, M.; BRUGAT, T. et al. The Role of the Spleen in Malaria. Cellular Microbiology, [Accepted Article], 2011.

PORTILLO, H. A DEL; LANZER, M.; RODRIGUEZ-MALAGA, S.; ZAVALA, F.; FERNANDEZ-BECERRA, C. Variant genes and the spleen in Plasmodium vivax malaria. International journal for parasitology, v. 34, n. 13-14, p. 1547-54, dez 2004.

PORTO, A P. N. A DE; LAMMERS, A J. J.; BENNINK, R. J. et al. Assessment of splenic function. European journal of clinical microbiology \& infectious diseases : official publication of the European Society of Clinical Microbiology, v. 29, n. 12, p. 1465-73, dez 2010.

POWELL, S.; SZKLARCZYK, D.; TRACHANA, K. et al. eggNOG v3.0: orthologous groups covering 1133 organisms at 41 different taxonomic ranges. Nucleic Acids Research, v. 40, n. D1, p. D284-D289, jan 2012.

PRICE, R. N.; TJITRA, E.; GUERRA, C. A. et al. Vivax Malaria: Neglected and Not Benign. Am J Trop Med Hyg, v. 77, n. 6_Suppl, p. 79-87, dez 2007.

ROUILLARD, J.-M. OligoArray 2.0: design of oligonucleotide probes for DNA microarrays using a thermodynamic approach. Nucleic Acids Research, v. 31, n. 12, p. 30573062, jun 2003.

ROYCE, T. E.; ROZOWSKY, J. S.; BERTONE, P. et al. Issues in the analysis of oligonucleotide tiling microarrays for transcript mapping. Trends in genetics : TIG, v. 21, n. 8, p. 466-75, ago 2005. 
RYDER, E.; JACKSON, R.; FERGUSON-SMITH, A.; RUSSELL, S. MAMMOT--a set of tools for the design, management and visualization of genomic tiling arrays. Bioinformatics (Oxford, England), v. 22, n. 7, p. 883-4, abr 2006.

SARAÇ, O. S.; ATALAY, V.; CETIN-ATALAY, R. GOPred: GO molecular function prediction by combined classifiers. Plos one, v. 5, n. 8, p. e12382, jan 2010.

SILVERMAN, B.W., (1986). Density Estimation, Chapman and Hall, London. UK.

SINGH, H.; PARAKH, A.; BASU, S.; RATH, B. Plasmodium vivax malaria: Is it actually benign? Journal of infection and public health, v. 4, n. 2, p. 91-5, jun 2011.

SU, X.-Z.; JIANG, H.; YI, M.; MU, J.; STEPHENS, R. M. Large-scale genotyping and genetic mapping in Plasmodium parasites. The Korean journal of parasitology, $v$. 47, n. 2, p. 83-91, jun 2009.

TAN, J. C.; MILLER, B. A; TAN, A. et al. An optimized microarray platform for assaying genomic variation in Plasmodium falciparum field populations. Genome biology, v. 12, n. 4, p. R35, 8 abr 2011.

THORNTON, J. M. From genome to function. Science (New York, N.Y.), v. 292, n. 5524, p. 2095-7, jun 2001.

TJITRA, E.; ANSTEY, N. M.; SUGIARTO, P. et al. Multidrug-resistant Plasmodium vivax associated with severe and fatal malaria: a prospective study in Papua, Indonesia. PLoS medicine, v. 5, n. 6, p. e128, jun 2008.

UDOMSANGPETCH, R.; KANEKO, O.; CHOTIVANICH, K.; SATTABONGKOT, J. Cultivation of Plasmodium vivax. Trends in parasitology, v. 24, n. 2, p. 85-8, fev 2008.

VINAYAGAM, A.; KÖNIG, R.; MOORMANN, J. et al. Applying Support Vector Machines for Gene Ontology based gene function prediction. BMC bioinformatics, v. 5, p. 116, ago 2004.

VINAYAGAM, A.; VAL, C. DEL; SCHUBERT, F. et al. GOPET: a tool for automated predictions of Gene Ontology terms. BMC bioinformatics, v. 7, p. 161, jan 2006. 
WERNERSSON, R.; NIELSEN, H. B. OligoWiz 2.0--integrating sequence feature annotation into the design of microarray probes. Nucleic acids research, v. 33, n. Web Server issue, p. W611-5, jul 2005.

WESTENBERGER, S. J.; MCCLEAN, C. M.; CHATTOPADHYAY, R. et al. A systemsbased analysis of Plasmodium vivax lifecycle transcription from human to mosquito. PLoS neglected tropical diseases, v. 4, n. 4, p. e653, jan 2010.

XIE, Z.; HU, S.; QIAN, J.; BLACKSHAW, S.; ZHU, H. Systematic characterization of protein-DNA interactions. Cellular and molecular life sciences : CMLS, v. 68, n. 10, p. 1657-68, maio 2011.

ZHOU, Y.; ABAGYAN, R. Match-only integral distribution (MOID) algorithm for high-density oligonucleotide array analysis. BMC bioinformatics, v. 3, p. 3, jan 2002. 